\title{
Handedness Development: A Model for Investigating the Development of Hemispheric Specialization and Interhemispheric Coordination
}

\author{
George F. Michel id
}

check for updates

Citation: Michel, G.F. Handedness Development: A Model for Investigating the Development of Hemispheric Specialization and Interhemispheric Coordination. Symmetry 2021, 13, 992. https:// doi.org/10.3390/sym13060992

Academic Editor: Gillian Forrester

Received: 5 May 2021

Accepted: 28 May 2021

Published: 2 June 2021

Publisher's Note: MDPI stays neutral with regard to jurisdictional claims in published maps and institutional affiliations.

Copyright: (C) 2021 by the author. Licensee MDPI, Basel, Switzerland. This article is an open access article distributed under the terms and conditions of the Creative Commons Attribution (CC BY) license (https:/ / creativecommons.org/licenses/by/ $4.0 /)$.
Psychology Department, University of North Carolina Greensboro, P.O. Box 26170, Greensboro, NC 27402-6170, USA; gfmichel@uncg.edu

\begin{abstract}
The author presents his perspective on the character of science, development, and handedness and relates these to his investigations of the early development of handedness. After presenting some ideas on what hemispheric specialization of function might mean for neural processing and how handedness should be assessed, the neuroscience of control of the arms/hands and interhemispheric communication and coordination are examined for how developmental processes can affect these mechanisms. The author's work on the development of early handedness is reviewed and placed within a context of cascading events in which different forms of handedness emerge from earlier forms but not in a deterministic manner. This approach supports a continuous rather than categorical distribution of handedness and accounts for the predominance of right-handedness while maintaining a minority of left-handedness. Finally, the relation of the development of handedness to the development of several language and cognitive skills is examined.
\end{abstract}

Keywords: development; handedness; lateralization; hemispheric specialization; interhemispheric coordination; embodiment

\section{Introduction}

There is a general consensus among neuroscientists that the human left and right hemispheres of the brain have different perceptual, motor, emotional, and cognitive functions with the most distinctive difference of a left-hemisphere predominance in praxis (e.g., gestures and tool use) and language (speech and comprehension) functions [1]. However, many have argued that the phenomenon of hemispheric specialization of function is poorly specified as to what functions are separated between hemispheres and how functions interrelate both within a hemisphere and across hemispheres (e.g., [2,3]). In addition, the mechanisms that underlie these hemispheric differences in function are unclear (cf., [4]). Finally, there is little research focused on describing how the functional specialization of the hemispheres develops [5] or what role interhemispheric communication plays in that development. Thus, there is much opportunity for research.

When I began my investigations of the development of handedness more than 45 years ago, I did so because I thought that the development of handedness could be a suitable model for how other forms of hemispheric specialization of function might be investigated developmentally. In 1970, as a graduate student, I had spent a week in Roger Sperry's lab testing the intermanual transfer of haptic weight and size perception in patients with callosotomies (some work that I did as an undergraduate student revealed hand differences in haptic perception and that had prompted my invitation). Although the results were inconclusive, I became fascinated with the issue of hemispheric specialization. At the time (and still today), the assumption was that hemispheric specialization of function derived from the hemispheric specialization of neuroanatomical circuits supposedly controlled by genes during development. 
I was trained by comparative psychologists, who, contrary to most Ethologists, argued that the development of species-typical behaviors required systematic investigations of individual-environment coactions [6-8] and not the interaction between genetic and environmental processes. I was trained to seek explanations that account for those phase transitions during development that result in a species-typical trait and to expect that the explanation would involve a complex array of reciprocal coactions between the individual's physiology and its environment. To study the development of a trait required: (1) detailed descriptions of the trait; (2) description of the course of its manifestation during the lifespan (or at least the period of focus for the research); (3) specification of the physiological processes related to its manifestation; (4) specification of the social/physical environmental characteristics that are the context of development; and (5) identification of how those physiological processes and contextual characteristics create the experiences involved in the individual's developmental expression of that trait [9]. The discipline of developmental psychobiology provides research strategies for examining how the dynamic bidirectional relationships between the individual's physical and social environment and their physiological processes operate to construct the developmental pathways of species-typical behaviors [10].

For example, as part of Lehrman's (e.g., [11]) programmatic investigations of the development of the ring dove reproductive cycle, my dissertation research focused on the role of experience for the initiation and maintenance of the incubation phase. The dove's cycle is a species-typical sequential pattern of courtship, nest-building, incubation, and brooding behavior with concomitant physiological phases (both hormonal and neural). My work demonstrated the importance of the conditions established during the earlier nestbuilding phase of the dove's first cycle (pair-bonding, nest-building, and their concomitant hormonal changes), which prepared the dove's nervous system and general physiology (e.g., formation of a "brood patch") and that helped create those experiences (the production of a nest and the presence of a nesting mate) that facilitated the transition to the subsequent incubation and brooding phases. The actual experience of engaging with eggs (the defining focus of incubation) is irrelevant for the initiation of incubation but is relevant for the maintenance of incubation and the initiation of brooding (cf., [12] for details).

Thus, the transition to and maintenance of each phase of the dove's first reproductive cycle requires concurrent social (mate and colony behaviors) and physical (nesting material and nest-site) and experience-elicited modulation of hormones (specific to each phase) that operate on a nervous system prepared by both the effects of the immediately previous and past experiences and previous and concurrent hormonal condition of the dove. For subsequent cycles, the neural and hormonal physiology of reproductively experienced doves function somewhat differently from that of reproductively naïve doves, but they still require much of the web of reciprocal causality among physiological conditions, social and physical conditions, plus the experiences operative during the first cycle.

Working out the details of the individual-environment transactions during the development of species-typical behaviors constitutes part of the discipline of developmental psychobiology $[10,13,14]$. What appears to be an innate, instinctive, relatively rigid pattern of reproduction in the dove is highly dependent upon the reciprocal coaction of a complex array of previous experience and hormonal conditions and concurrent social and physical stimuli. The alteration of any aspect of this array can have formative influences on the pattern and even interfere with reproduction. These factors become autogenously choreographed into a web of causation that exhibits extensive feedback and reciprocal influences but ensures the manifestation of the species-typical behavior appropriate for the species-typical ecological conditions. Adherence to a linear causal explanatory process (e.g., the interaction of nature and nurture in which the proportion of influence of each and the interaction may be separately estimated) distorts the complex transactions among multiple levels of influence in the development of any trait. Developmental psychobiological research provides examples of how several common species-typical behaviors develop $[9,10]$. 
In the mid-1970s, I sought to transfer my graduate training to the study of the development of hemispheric specialization for language (a human-typical trait). However, the category "language" involves a wide range of characteristics with different abilities and skills that are typically grouped together based on little more than convention. Moreover, with the exception of the production/comprehension distinction, these different characteristics are often substituted for one another when investigating hemispheric functioning on the assumption that they all represented the same underlying neurobiological process. Since most research focused on the language abilities involved in the production and comprehension of speech, this meant that broad inferences had to be made about what constituted language production or comprehension during infant development.

Since handedness (another species-typical trait exhibiting hemispheric specialization) could be defined by the actual actions of the infant, without extensive inference on the part of the investigator, I thought that it would be more suitable for the study of the development of hemispheric specialization during infancy. Handedness ought to be more easily identified, and its developmental changes ought to be measured more precisely than language. In addition, at that time, the mechanisms responsible for lateralization of handedness and language functions were thought to be related $[15,16]$.

Recently, there has been a growing consensus that the handedness and language functions of the left hemisphere are not causally related ([17,18], but see [19]). In part, this is because we lack suitable models of the distribution of each and therefore have no way of assessing whether their joint probability occurs by chance. For example, dichotic listening data from 1554 individuals revealed that over $82 \%$ of participants had left-hemisphere language comprehension [20]. However, no relation was identified with handedness (as measured by common questionnaire results), leading the authors to conclude that it is unlikely that handedness and language lateralization are associated. However, the analysis of the association assumes that the joint probability of their association derives from each having a distribution centered on "no differences" between the hands or the hemispheres. Of course, no matter the relation of handedness and language laterality, demonstrating how to use a developmental psychobiological perspective to investigate the developmental processes involved in handedness could encourage other researchers to use this perspective to discover the development processes involved in other lateralized functions [21-24].

During my investigations of the development of handedness, I discovered that I had a somewhat atypical way of conceptualizing (1) development; (2) the character of science; and (3) human handedness $[14,23,25,26]$. My conceptions derived from my background training in comparative psychology and developmental psychobiology (cf., $[9,27])$. To understand the difference in developmental conceptions, consider this conclusion from a recent review of the neuroimaging work on adults who had been forced to use their right hand for acquiring the skill of writing. "Together, the functional and structural neuroimaging studies on forced right-handedness show that the adult brain holds an accumulated record of both innate biases of preferred hand use (nature) and early developmental experience (nurture)" (p. 3, [28]).

Thus, without examining the literature on the early development of handedness, the authors consider the acquisition of writing skills (in school-aged children) to be the only "early" developmental experience that could have affected the structure and functioning of the adult brain. Moreover, they assume that development is a process of the interaction between nature and nurture factors in which the influences of each can be readily identified by specific neural structural and functional consequences. Therefore, before presenting my evidence of how the development of handedness might serve as a model for investigating the development of other aspects of hemispheric specialization and interhemispheric communication, I must describe how I conceive of the character of science, human handedness, and development.

I present my conceptions only to contextualize my own research and not to provide a comprehensive account of handedness and lateralization. There are several excellent comprehensive accounts available (e.g., [29-31]) that I highly recommend. 


\section{Character of Science}

Since Ethologists frequently challenged the research of my mentors (cf., [32]), my doctoral training involved strict adherence to Popper's [33] falsifiability approach when designing research studies. That is, the research project had to be designed to challenge my hypothesis; that is, the design had to have the potential of producing results that were counter to those predicted. Too many researchers believe that the presence of a control group and a statistical test of the null hypothesis prevent the occurrence of confirmation bias in their experimental designs. Unfortunately, the null hypothesis simply assumes no differences between groups - it does not reveal the falsifiability of the hypothesis.

For example, showing statistically significant similarities among right-handers across age and revealing that the similarities are unlikely to occur by chance is a confirmation bias. A developmental explanation for why right-handedness prevails in the population could only be falsified if left-handers exhibited the same developmental factors as those who develop right-handedness. If, as I hypothesized [34], a neonate's preference to orient the head rightward is a developmental precursor to the later development of a right handuse preference, only the development of those infants with a left head orientation could challenge this hypothesis. Infants with leftward head orientation preferences must develop left-hand-use preferences, which they do [35].

Recently, Strevens [36] argued that science has come to alter the course of civilization during the past 400 years, not because of its adherence to some fictional notion of a scientific method that scientists employ in an objective, non-passionate manner. On the contrary, he notes that scientists pursue their questions about the nature of reality with the same human biases of personal proclivities, attitudes, opinions, desires, experiences, group affiliation, popular fashions, and fancies as anyone else. According to Strevens, what makes science unique is that scientists have agreed to use an iron rule of explanation in their discourse. This iron rule requires that all scientific disputes be conducted with reference to empirical evidence.

To be sure, previous to the institution of science, arguments were supported by rhetorical "evidence" - usually in the form of personal anecdotes, testimonials, case studies, casual observations, thought experiments, etc.- - selected to support the argument. However, modern science eschewed such evidence in favor of that acquired via systematic observation, especially when variables could be manipulated by the researchers so as to observe the effect of the manipulation on other variables. This method became the gold standard of evidence required by the iron rule. Adherence to the iron rule forces scientists to uncover and generate new data to support their arguments. This rule channels the scientist's passions (hope, envy, ambition, anger, resentment) and ideology into the production of empirical evidence.

According to Strevens, the iron rule of explanation created a new manner of human communication with arguments based upon the presentation of empirical evidence rather than upon techniques of rhetorical persuasion (still characteristic of modern non-scientific debates and marketing techniques). Thus, although individual scientists have their own values, biases, and goals, the iron rule permits science to progress. Since scientists gather data for the purpose of disputation, progress can be made empirically, even when there is a lack of conceptual clarity. This data-gathering process gradually builds a consensus about which research paths should be abandoned and which should be supported. Consequently, consensual understanding (a conventional wisdom) is achieved.

Because of the iron rule, the scientist has a limited number of options to engage in scientific communication: (1) the scientist can lie about the collected data; (2) the data may be distorted inadvertently; (3) the collection of the data may be conducted in a sloppy manner via insufficient attention to the structure of the research design (e.g., poor selection of subjects for observation, confounding in the manipulation of the variables tested, inadequate or inappropriate statistical analyses); (4) data can be cherry-picked to support the argument (this can happen, either deliberately or not, when the data collection enterprise becomes so vast that it is difficult for any one scientist to be cognizant of all of 
the data); (5) contradictory data simply can be ignored; and (6) finally, scientists can pay extraordinary attention to the details in the design and conduct of their research and when analyzing and interpreting data. Only by adhering to this last option can the scientific enterprise progress, and this adherence is the reason why science has been able to transform the trajectory of civilization [36].

For Strevens, science is not self-correcting; rather, the collection of evidence on a vast scale eventually swamps bad data and incorrect arguments. Although there is much that I admire in Strevens' account of science, I believe that he fails to adequately incorporate the contributions of Kuhn [37,38] and Popper [33]. Kuhn correctly noted the "fashionable" aspect of what he called "normative science". Scientists readily add empirical evidence to a popular hypothesis or theory by conducting studies designed to confirm the hypothesis (demonstrate an effect that is unlikely to occur by chance). This confirmatory process creates conventional wisdom in each of the various disciplines of science. It is this confirmatory process that prompted Popper to argue that science can only progress via a process of conjecture and refutation. Popper argued that scientific studies should be designed to challenge the tested hypothesis (conjecture), not seek evidence in its support. By deliberately seeking the occurrence of data that a hypothesis claims cannot occur, only then can the hypothesis be evaluated. If contradictory evidence begins to accumulate, then the hypothesis must be reevaluated.

Unfortunately, it may not be possible to always design a "refutation" study. My own research has been constrained by the contingencies of working with human infants and the pressures of academic publication requirements. However, I have tried to include in my research designs the ability to collect data that would contradict my hypotheses. I have done so because if the results do not match those predicted, they still reveal something about the phenomenon of study, unlike simply failing to reject the null hypothesis.

Since most tested hypotheses in lateralization research derive from the conventional wisdom of the discipline, any failure of the data to support the hypothesis can be interpreted as resulting from a weak design, and the results may go unreported. In addition, any difference from a control group is taken as support for the hypothesis. Thus, it is possible for the confirmation bias of normative science to result in an accumulation of evidence that can swamp not just "bad data" but also data and/or interpretations that otherwise conflict with the conventional wisdom. Moreover, the research enterprise can become so vast that many researchers (myself included) may fail to be aware of all of the relevant data. Google Scholar search on April 2021 lists over 402,000 articles on handedness. Hence, reviews, hypotheses, and theoretical accounts often suffer from missed or ignored data (the present paper included).

It is my contention that much of the study of hemispheric specialization and interhemispheric communication (HS/HC) is constrained by conventional wisdom that inhibits the discovery of the developmental processes involved. Indeed, many critical reviews of HS/HC note problems of inadequate statistical power, missing details on proportion of those showing atypical lateralization, and the use of many different, often insufficiently validated, methods to ascertain functional lateralization $[3,39,40]$. Thus, there are too many instances of failures of replication [41], poor research designs [42], and the accumulation of conflicting evidence that fails to support any explanation of the character of HS/HC (e.g., $[43,44])$ or for the mechanisms responsible for the specialization [45].

Please note that I am not advocating for a rejection of the conventional wisdom; I am only noting that too many studies are not designed to challenge it, and hence, we cannot know whether the consensus adequately represents the reality of HS/HC. For handedness, explanations must account for, at least, the apparent continuous distribution of skill differences between the hands, the maintenance of a distinct minority of "left-handers" in the population, the reasons for a distinctly smaller proportion of complete left-hand use among left-handers as compared to the large proportion of complete right-hand use among right-handers. I propose that the adoption of a developmental psychobiological perspective may solve many of the problems confronting current explanations of HS/HC [46]. 
That perspective starts with some theoretical notions about the mechanisms underlying hemispheric specialization.

\section{Some Speculations about the Mechanism Underlying Hemispheric Specialization}

The typical functional labels for those processes that differ between hemispheres (e.g., language, spatial ability, positive emotions, theory of mind) hide many different simpler neural processes and circuits [46]. Only by identifying the precise differences in the processing circuitry between the hemispheres can we discover how particular functions come to be distinct aspects of hemispheric specialization. That identification requires that we unpack complex functional categories to reveal whether simpler processes could accomplish the same function. Currently, there are only a few hypotheses about such processing, but it is not unreasonable to presume that hemispheric differences reflect forms of information processing [47] via neural network architecture function that affect pattern perception and motor organization [48] and these underlie complex functional categories.

One theoretical notion is that complex visual, auditory, and haptic stimuli are composed of many spatial and temporal patterns of transitions in their activation of the sensory/perceptual systems and that these are hierarchically organized according to the relative frequency of the transitions (from low to high). Decades ago, Sergent $[49,50]$ proposed a frequency hypothesis of hemisphere processing, which proposed that identifying, comparing, and remembering the characteristics of any complex hierarchically structured visual, auditory, or haptic stimulus depends upon two neuronal systems. One system is more effective at processing higher frequency transitions in temporal and spatial patterns and, hence, it is better at distinguishing the sort of subtle details that enable discrimination of speech sounds, individual faces, printed letters, etc. The other system is more effective at processing lower frequency transitions and would be better at extracting the more global, or Gestalt, aspects of any stimulus (e.g., prosody, melody, emotional tone, relative position in space).

According to Sergent's hypothesis, analysis of high-frequency transitions is the typical processing ability of the left hemisphere; whereas, the analysis of low-frequency transitions is the typical processing ability of the right hemisphere (see also, [43] for a more modern perspective). Thus, the prosodic characteristics of speech sounds would be processed by the right hemisphere because they reflect low-frequency transitions [51].

This differential processing, however, does not mean that the hemispheres must be distinctly different in their information processing ability. Both hemispheres might be capable of processing information that is in their nonpreferred range but not as proficiently [49]. Indeed, it is likely that there are circuits within each hemisphere that operate in such a manner that they mimic the apparent information processing of the opposite hemisphere. My point is that we know too little about the processing underlying the presumed functional differences between the hemispheres for us to rely on intuitive notions of what makes the functions different. Moreover, the developmental experience of success in a usual processing mode, in combination with interhemispheric inhibition (via the corpus callosum, among other mechanisms), would likely constrain the ability of the hemispheres to readily shift from their typical processing modes. Since the frequency and temporal characteristics of stimuli do not always align with clear distinctions of the functional organization (e.g., language vs. spatial), it is not always the case that verbal visual information or speech sounds would reveal a left-hemisphere processing advantage or that visuospatial stimuli would reveal a right-hemisphere advantage. For example, the right vs. left ear advantage in dichotic listening tasks might depend on the relative frequency of the presented stimulus [52], among other factors. The right ear (left hemisphere) advantage would be recorded for the higher frequency of two tones, irrespective of whether they represent speech or noise (e.g., [53,54]). Similarly, the right hemisphere exhibits an advantage in the processing of low-frequency information regardless of the stimulus type [55]. However, developmental events might modulate this difference. 
In tonal languages, correct detection of tonal qualities of speech sounds (usually associated with prosody) is necessary for understanding the meaning of those sounds. Therefore, native Mandarin speakers demonstrated right-ear advantage (left hemisphere) for tonal inflection, whereas English speakers tested on the same stimuli exhibited no asymmetry $[56,57])$. Although the Norwegian language is also tonal, Norwegian speakers exhibited a right-ear advantage for tonal qualities of their language, but not for tonal sounds typical for Mandarin [57,58]. This demonstrates a developmental dependency for lateralization. In addition, Zulu language speakers exhibited a right-ear advantage for processing click consonants of the Zulu language, whereas English speakers did not show this pattern [59]. Thus, as a result of developmental experience, the degree of activation in the left-hemisphere temporal cortex depends on experience in a language-based context, rather than just the characteristics of sounds [60].

Hypothesizing a difference between hemispheres in frequency analysis helped clarify the confusing observation of a right-hemisphere advantage at discriminating a face from non-face stimulus [61] and a left-hemisphere advantage for discriminating two faces that differ in just one feature; the latter requires a higher spatial frequency analysis (e.g., [49,62]). Thus, neither functional categories nor simple notions about processing strategies (spatial and temporal frequency analysis) characterize the differences between the hemispheres because developmental experiences (with faces, native language sounds, etc.) contribute to the shaping of hemispheric differences. Developmental psychobiological research frequently shows that the developmental origins of species-typical traits often begin with nonintuitively obvious patterns that may be quite distinct from the forms manifested later [10]. For example, face-selective neural activity in the right hemisphere of four-monthold infants is mediated by the presence of a maternal body odor [63]. Thus, early exposure to the mother's face during feeding and close contact permitted the maternal odor to enhance right-hemisphere face processing, and this enhancement was not a consequence of arousal or visual attention in the maternal odor context.

What is frequently missing from spatial and temporal frequency notions of hemisphere differences in processing hierarchically structured stimulus patterns is that the hemispheres also differ for the construction of actions. Data from animals [64] and humans [65] show that the left and right hemispheres of the brain confer asymmetric contributions to the organization and manifestation of sensorimotor processes and manual actions. Therefore, motor behaviors can be informative behavioral markers of asymmetric brain function and organization. Sainburg's [66] dynamic-dominance hypothesis of motor lateralization proposes that for right-handers, the right arm engages in predictive control so as to produce smooth and efficient movements as the left arm ensures stability to unanticipated perturbations [67]. For left-handers, predictive control is more shared between hands than in right-handed individuals [68], suggesting that left-handedness is not the mirror image of right-handedness (cf., $[69,70])$. Although there is much evidence to support this hypothesis [71], the neural bases of motor lateralization and handedness are not clear [72].

The left hemisphere is typically involved in the production of precisely timed, serially ordered quick movement patterns that contribute to the articulation of speech sounds, as well as sophisticated manual actions manifested in object manipulation, artifact construction, tool use, imitating actions, and communicative gestures and pantomiming. In contrast, the right hemisphere seems to provide the postural and contextual support for the manual actions produced by the left hemisphere. Trajectory control and visual feedback for movement of the preferred right arm are processed more accurately, whereas positional control and proprioceptive feedback are processed more accurately with the nonpreferred left arm (e.g., [73]). Indeed, there are complementary specializations of each hemisphere for different aspects of the manual control involved in a role-differentiated bimanual manipulation (RDBM - the preferred hand holds the needle in sewing or the lid when unscrewing a jar, etc.) task [74]). Again, these differences are relative, not absolute.

Moreover, human motor cortical organization of control of arm and hand muscles is influenced by handedness (as measured by the Edinburgh Handedness Index - [75]). The 
cortical representation of the muscles for the preferred limb of both left- and right-handers is larger. Changing handedness through practice, either willingly or if obliged by injury, is not easy. However, a review of the studies examining brain activation and hand skills after such handedness shifts reveals that practice seems to play a significant role in the formation and consolidation of both neural and behavioral asymmetries [76]. Since the motor cortex has extensive interconnections that can permit experience-based potential for functional reorganization (e.g., [77]), any asymmetry of use would lead to increased practice of the preferred hand and further enhance the skill of that hand. Living in a society that strongly favors the use of the right hand could encourage enhanced use of the right hand for the control of trajectory and the left hand for positional control during development, even for those developing a left-hand-use preference. Thus, left-handedness would not be the mirror of right-handedness in neural structure or function.

Both hemispheres potentially appear to be capable of processing any type of information, whereas the relative spatial or temporal frequency pattern of the information, its complexity, and socio-cultural experiences and practice aspects would influence which hemisphere might cope with a particular task more effectively. Both hemispheres may be capable of controlling precisely timed, sequentially organized muscle contractions and relaxations that underlie the ability to manifest serially ordered speech and manual skills. However, the skill differences that come from experience (cf., [78]) and the influence of interhemispheric communication (both inhibition and facilitation) likely contribute to how the hemispheres become functionally lateralized during development. Therefore, it is not correct to state that there is a distinct division of processing ability between the two hemispheres or that the left hemisphere controls language functions while the right hemisphere controls visuospatial skills.

There are two important caveats for understanding hemispheric specialization. First, the division of labor between the hemispheres has a relative rather than an absolute character that seems to be established during development. This means that the type of information processing, or action programming, is more important for the distribution of work between the two hemispheres than our linguistic labels for such phenomena. Second, although the two hemispheres become structurally and functionally distinct during development, they are still deeply connected via the corpus callosum and other integrating networks: they have access to and can potentially process any type of information needed for the manifestation of any skill. Therefore, the development of callosal functioning should be of major concern in developmental studies of hemispheric specialization. The development of specialization can be influenced by how and when the different forms of processing control are shared across hemispheres.

\section{Character of Human Handedness}

Laterality refers to asymmetries of bilateral structures (including neural structures) and left-right biases in function and behavior. Laterality has been demonstrated in species from all major vertebrate classes and in many invertebrates (cf., [79]). Some have considered this evidence of evolutionary conservation (cf., [5]), which suggests strong evolutionary pressure (something akin to the pressure responsible for the rostral-caudal and dorsalventral asymmetries). As yet, no mechanism has been identified for establishing the human brain's right-left axis [80]. However, data from over 32,000 adult participants found that 21 DNA loci were associated with different aspects of brain asymmetry [80]. These loci were near genes involved with prenatal development and microtubule organization and functioning, which led the authors to suggest that cellular chirality may influence the development of right-left asymmetry of the brain.

In humans, laterality typically refers to a division of functional processing between the two cerebral hemispheres. The pattern of functional asymmetry often is explained as preventing conflict between duplicate functional regions, enhancing parallel processing, and reducing redundancy and increasing neural capacity (cf., [81]). Oddly, in individuals 
with atypical lateral asymmetry of organs, there does not appear to be atypical functional lateralization of the hemispheres $[80,82]$.

Although most of the reviews (cf., [83]) and theorizing (cf., [84]) focus more on the advantages and potential evolutionary adaptiveness of lateral asymmetry than on its phylogeny (evolutionary history), it is difficult to specify the benefits (vs. costs) for many lateral asymmetries [5]. Laterality at the individual level supposedly provides advantages by increasing efficiency in the neural organization [81], for foraging [85], for monitoring predators [83], for numerical abilities [86], etc. Laterality at the population level supposedly facilitates behavioral coordination among asymmetrical individuals of the same or different species (e.g., [87-89]).

However, consider human handedness: it is likely that handedness reduces the decision time for the initiation of unimanual tasks (putting food in mouth, throwing or swinging a stick) and for the selection of the different actions in role-differentiated bimanual manipulations (RDBM). During RDBM, the preference efficiently dictates the sequence of the actions of each hand, and the practice of manual actions improves their skill of execution. It is possible that a population-level hand preference may facilitate the acquisition of manual skills via imitation ([90]; but see [91]). However, it is more difficult to specify benefits and costs for the population to have a prevalence for a particular form of handedness (e.g., right-handedness) unless it is an artifact of some other form of lateral asymmetry (e.g., hemispheric control of language functions, [29]). If the latter, then there must be benefits to maintaining a minority form (left-handedness, e.g., [92,93]) or an atypical hemispheric separation of functions [3]. Currently, that advantage is unknown.

The human population-level laterality is the left-hemisphere specialization for language and praxis and the right hemisphere for spatial attention, face recognition, and prosody of speech. However, there is some evidence that atypical functional segregation in the hemispheres may not be very rare in the general population [3]. Therefore, investigation of those individuals with atypical functional segregation ought to be a priority for understanding notions of "neural crowding" and the value of "complementarity" in theories about the benefits of HS/HC. As yet, any distinct disadvantages for individuals who fail to exhibit the typical pattern of lateralization have not been demonstrated [94]. Moreover, there are many aspects of both cortical and subcortical neural functioning for which there appears to be neither evidence of any lateral asymmetry nor evidence of inefficiency or disruption as a consequence of their symmetry.

Although five non-mutually exclusive theories have been proposed to account for the population predominance of human right-handedness (cf., [95]), the postural theory [96,97] seems to be the most popular. This theory proposes that manual laterality evolved in primates from structural and functional adaptations for unimanual feeding (initially arboreal and requiring three limb support for acquiring food with the free limb that shifted when terrestrial species evolved). Unfortunately, none of the five theories adequately accounts for the predominance of right-handedness in humans or for the consistent minority of left-handers (cf., [98]).

Indeed, one problem with accounting for the evolution of human handedness is the assumption that all aspects of handedness are derived from the same underlying mechanisms and reflect the same phylogenetic history. When explanations for population-level asymmetries of hand-use preference are made, they fail to distinguish between homologous and convergent laterality [99]. The issue of underlying identity is an important feature of character specification in taxonomy and phylogeny. Are traits similar across species or across ontogenetic phases within a species because of homologous (derived from the same ancestral character) or convergent (adapted to similar ecological conditions) evolution?

Handedness exhibits similarities across species (in the form of preferred limb use) and similarities across development within an individual. However, to pursue the developmental psychobiology of handedness, I use the concept of homology to extrapolate from experimental research on the neural mechanisms involved in the control of limb use in 
certain model mammals to my neural explanations of the differences in how the preferred and nonpreferred hands are controlled in humans (see Section 6).

Thus, I infer, from experiments involved in controlling hand use in specific primate species, that differences in visual, haptic, and proprioceptive experiences between the hands result in differences in their neuromotor control mechanisms. In turn, these differences in control concatenate through continued use into distinct differences in neural circuitry between the left and right hemispheres of the brain [100]. However, I do not assume the homology of hand-use preferences among primates. Throwing a stick or rock to hit a target relies on the same homologous structures (skeletal musculature, visual-motor neural pathways, and likely sensorimotor coding processes) as hurling a javelin or pitching a baseball, but that does make them homologous actions. It is more likely that they are related via functionally prompted transfer of skills [101].

There are five criteria for identifying homology [99,102]; three concern morphological structures, and two concern behavioral functions, specifically. The latter two include: (1) movements may be homologous if they employ homologous structures (defined by any of the three morphological criteria) in similar ways; (2) behaviors dependent on homologous regions of the brain are homologous [103]. Since structure affects function, behavioral similarities can be biomechanically induced without representing homology. In addition, since strikingly dissimilar behaviors can depend on homologous brain regions in vertebrates [102], this weakens their use for specifying behavioral homologies.

Therefore, identifying a behavior as homologous because of similarity of the movement pattern, the employment of homologous structures for the movement, or when relying on homologous aspects of the nervous system requires extra caution. Throwing sticks and rocks are unlikely to be homologous across ape species but rather simply transferred skills prompted by: (1) functional goals of hitting a target with an object; and (2) constrained by the characteristics of the object (e.g., aerodynamics, manual affordances, and physical mechanics); (3) the conditions of the context (e.g., wind, speed of action, distance to the target, relative positions of subject and target); and (4) the constraints from the biomechanics of the limb [104].

According to Atz [102], using the construct of homology in behavior research requires: (i) robust descriptions of the organism's behavioral repertoire; (ii) extensive comparative work on both the morphology of effector structures and the structure-function relation for the neural processes across a wide range of species; and (iii) detailed descriptions of developmental processes, especially in closely related species. All of these requirements are missing from the investigation of hemispheric specialization of function, including handedness [99]. There was no evidence to support the notion that the hand preferences (however defined) exhibited at different phases of development (prenatally, infancy, toddlerhood, preschool, preadolescent, adolescent, adult, etc.) represent different manifestations of the same underlying trait in the manner of serial homology. Therefore, human handedness is likely a convergent trait that evolved independently among different primate species and that emerges across developmental phases as ontogenetic adaptations to the ecological conditions specific to each different phase [105]. However, if handedness does represent ontogenetic adaptations, then any account of its development must address how it can exhibit the same preference (e.g., right hand) across different phases of ontogeny (see Section 9).

The lack of homology of hand preferences during development requires that each type of preference must be examined in relation to both concomitant developmental changes in brain structures/functioning and developmental changes in cognitive, emotional, and social abilities. In addition, each of these abilities must be carefully described according to their sensorimotor character and not just by their functional consequences. For example, careful description reveals patterns of infant facial expression that evoke perceptions of infant emotions by observing adults [106], but these patterns really reflect coordinative structures of movement synergies for the infant and not expressions of emotion [107]. 
How those coordinative structures develop into expressions of emotion has not been systematically investigated but should be (cf., [108]).

Of course, a "deep homology" could be identified if the same DNA information relates to the different forms of handedness. Since hemispheric specialization is considered to be the result of genetically determined processes of neural circuit formation, it is not surprising that handedness also would be considered to be genetically determined. Studies of large populations have been disconcerting because they have failed to reveal any Mendelian character to handedness. Moreover, these studies have shown that genes account for only a minor proportion of the variance of handedness in the population. Indeed, heritability estimates for handedness are in the range of 0.23-0.45 [109-113]. Elsewhere [10,93,99], I have noted that heritability estimates do not reveal the degree of genetic influence on a trait. Rather, heritability estimates only identify the relative ease by which controlled breeding manipulations could change the distribution of a trait in the population. Moreover, such heritability estimates for breeding require that there be no changes in the environmental conditions; otherwise, the estimates can change.

In a study of over 12,000 subjects, using their own non-psychometrically evaluated questionnaire [114], but not using heritability estimates, Perelle and Ehrman [115] reported that $76 \%$ of right-handed and $61 \%$ of left-handed subjects had reported no left-handed first-degree relatives. A recent meta-analysis of 35 samples from studies of twins that employed techniques for estimating heritability found that additive genetic effects account for $25 \%$ (95\% Confidence Intervals $=16-30 \%)$ of the variance in handedness, with the remainder associated with unique non-shared environmental effects [111]. Similarly, a large study of Australian and Dutch twins and their family members estimates that $25 \%$ of the variance in handedness is attributable to additive genetic effects [111]. In a sample of 30,161 adults in Finland [45], unique environmental effects accounted for most of the observed variability of handedness, both in childhood (92-100\%) and adulthood (74-86\%).

Based on self-reported handedness from over 72,000 offspring, McManus and Bryden [110] found that the prevalence of left-handed offspring with two left-handed parents was $26 \%$ and about $20 \%$ with one right-handed and one left-handed parent (only $10 \%$ with two right-handed parents). A higher proportion of left-handedness has been observed in children from left-handed mothers and right-handed fathers (L-R pair) than from righthanded mothers and left-handed fathers (R-L pair-[116-119]). McManus [119] estimated an increased frequency of only $0.4 \%$ of left-handedness in children of R-L pairs as compared with an increased frequency of $2.9 \%$ in children of L-R pairs, with higher left-handedness rates reported in male offspring in both sets (see also, [117]). Michel [93,120] provided evidence of some of the social interactive influences on offspring handedness, which derive from maternal-infant engagement with objects, that likely accounts for the greater left-handedness in offspring of R-L parents.

A meta-analysis of genome-wide association studies [121] estimated that the number of genetic loci that relate to handedness differences is likely to be between 40 and 100 . However, it is more likely that the $40-100$ loci are more related to specifying the receptors for specific neurotransmitters, their location within the neural cell membrane, the enzymes and proteins for the production, transport, storage, and release of the neurotransmitters involved with sensorimotor control of the actions of the hand and arm. Moreover, these molecular mechanisms may operate at different levels of the nervous system (e.g., spinal, brain stem, and cortical, [5]). They may have effects on other organ systems as well as other functions.

A large-scale (1,766,671 participants) genome-wide association study (GWAS) has revealed that 48 genetic variants are statistically associated with different forms of selfidentified handedness (41 with left-handedness and 7 with mixed-handedness [122]. Only $39 \%$ of the SNPs associated with left-handedness (about $11 \%$ of participants) overlapped with SNPs associated with mixed-handedness (about $2 \%$ of the sample), leading the authors to suggest that these handedness patterns may be unrelated. Note the rather small proportion of mixed-handedness in the sample, which raises questions about the 
assessment technique (see below). Associations with previously reported candidate genes for left-handedness were not found. In addition, there was no association with any of the genes exhibiting asymmetric expression early in development and only 1 of 43 genes that displayed asymmetric expression in cervical and anterior thoracic spinal cord segments in five human fetuses [123]. Since 8 of the 41 SNPs associated with left-handedness are close to genes relevant for microtubule formation and regulation, the authors suggest that these SNPs become related to left-handedness as a consequence of their influence on the role of microtubules in neural migration and the growth of axons and dendrites responsible for the synaptic formation of neural circuits.

Obviously, the GWAS was not conducted on brain samples, and this presents a problem since genetic expression may differ in brain tissue, and it may differ for developing brains compared to adult brains. However, even post-mortem expression in children's brains may fail to capture any potential patterns of expression that might contribute to the developmental trajectory of handedness. Since the study used self-identification as the measure of handedness, the results may be problematic (see below). Since the GWAS is not identifying genes that are commonly found associated with handedness in other primate species or across different phases of human development, these studies do not identify a deep homology for handedness. So, how does understanding the genetic association with handedness reveal the causes of handedness?

Investigations of the genetics of handedness presume that some kind of convergent pattern of altered gene expression must occur in certain regions of the brain of those individuals with the same handedness. Such a change in gene expression would underly and thus explain handedness. However, it is likely that an individual's handedness emerges from the trajectories and dynamics of neural activity derived from decades of development that includes common and idiosyncratic experiences [69]. Genetics, therefore, might have some influence in the initiation of the developmental trajectory of handedness, slightly affecting the probability of one form over another. However, genetics is unlikely to explain the developmental emergence of handedness in any direct or informative manner. Perhaps the strongest conclusion to be drawn from genetic analyses of handedness development is that there are no convergent patterns of gene expression that characterize the patterns of handedness; at least, not in analyses of peripheral tissue or in post-mortem analyses of the brain. Even a large-scale study of epigenetic DNA methylation failed to predict left-handedness [124].

It would seem to be a fool's errand to try to specify the genetics of handedness, much less to use it to distinguish homologous from convergent evolution. This is not to deny the necessary role of molecular neurobiological processes, in which DNA expression (and its epigenetic influences) plays a part in the manifestation of handedness. Thus, the studies of the genetics of handedness force me ([99], see also [5]) to conclude that: (1) handedness emerges from a developmental process in which genes play, at best, a very limited and indirect role; (2) there is unlikely to be any deep homology in either ontogenetic or phylogenetic handedness.

\section{Assessing Handedness}

As McManus, Van Horn, and Bryden [125] note, handedness is " . . that difference between the hands of which every right-hander and left-hander is entirely aware from their own behavior, but for which we have almost no adequate scientific explanation" (p. 394, emphasis added). For me, this definition of handedness aligns with only one method of handedness assessment, of which I count four. The first handedness assessment method is the most familiar and is associated with the human narrative identity ("I'm right-handed"). For most societies, handedness becomes a part of the person's identity similar to their sex, geographic locale (e.g., British, Parisian, Australian, Bostonian), familial ethnicity (e.g., Irish, Scandinavian, German, Italian, Persian, Thai, Taiwanese), etc. Like most forms of our narrative identity, the developmental precursors become observable during the second and third postnatal year and are marked by the production of such 
statements as "I am", "like me", etc. Therefore, the acquisition of symbolic language seems to be an important characteristic in the development of an individual's narrative or self-identified handedness. Once established, this handedness identity likely plays a role in the subsequent development of manual skills as children seek to make their skills concordant with their narrative identity.

Oddly, some societies have separate words for the right- and left-hand use (as in English), but they do not have a way of expressing a hand-use preference as part of their narrative identity (cf., $[69,126,127])$. Members can describe a preference for which hand they use for various manual activities (hammering, throwing, sewing with a needle, pulling the flesh while skinning an animal, etc.). Interestingly, the hand-use descriptive pattern that these societies use is very similar to a second method of assessing handedness: the self-report of the hand preferred for various manual actions (both unimanual and RDBM). This assessment method is represented by the 3 or 4 different questionnaires frequently used in neuropsychological research (e.g., the Edinburgh Handedness Index-EHI [128], the Waterloo Handedness Questionnaire-WHQ [129], Annett Questionnaire-AQ [130], Home Handedness Questionnaire-HHQ [131]).

Interestingly, the self-identity handedness fails to capture the individual variability that emerges when large samples of people are assessed via questionnaires. Indeed, the classification distribution for questionnaires is not as clearly categorical as that of selfidentity (but see, [132]) and the more varied the manual tasks addressed by the questions (usually 10-15 tasks but can be as many as 60+), the more individual variability that can be expressed. Of course, there are statistical procedures that can reveal latent categories of people by identifying the associative patterns among the answers to the questions [132]. There may be three or more dimensions of handedness on which people may differ [133], but see [134]) or as many as eight handedness types [130] depending on the type of analysis used and the number of questions in the questionnaire [94].

The answers on a questionnaire are typically reduced to a single score, a laterality index (LI-(often $(\mathrm{R}-\mathrm{L}) /(\mathrm{R}+\mathrm{L})$ answers)). Interestingly, this LI (sometimes called a laterality quotient-LQ) can be used for various measures of hemispheric specialization of function from fMRI [41] to observational measures of handedness [125]. All too often, researchers choose an arbitrary cut-off score for the index in order to create most often two, but sometimes three categories (to capture ambilateral individuals) of people's handedness. These categories provide some consistency between the questionnaire and the narrative identity pattern. Unfortunately, problems arise because arbitrary cut-off scores can vary across studies making the categories established less reliable.

For example, although the typical LI ratio does not indicate whether the difference between the hands (or hemispheres) is significant, a categorical dominance classification is often imposed. A standard method of dominance classification for fMRI [41] uses cut-offs at +0.2 and -0.2 to divide left dominance $(\mathrm{LI}>+0.2)$ from bilaterality $(-0.2 \leq \mathrm{LI} \leq+0.2)$ and right dominance ( $\mathrm{LI}<-0.2)$. Since such cut-offs are arbitrary, and Bradshaw et al. [41] found multiple studies that chose their own cut-off values, including $0.1,0.33,0.4,0.5$, and 0.6, using statistical classification techniques would provide some estimate of the reliability of the classification (e.g., for handedness, [34,135]; for fMRI, [136]). However, these techniques are seldom used (cf., [137]).

Indeed, variability in how handedness is assessed (e.g., parental report or measured hand-use preference), the type of handedness assessed (e.g., reaching or manipulation), methodology (ages of assessment, frequency of assessments, and time between assessments), and how the differences between the hands are defined $[135,138]$ is likely to have contributed to the conventional notion that handedness is unreliable and unstable before 6-10 years of age [139]. However, defining a hand-use preference by a simple difference between hands (a "handedness index", [140]) may create the impression that hand preferences are unstable across assessment ages. Whereas, defining a preference by statistical estimates of whether the intermanual differences are likely to have occurred by chance $[135,141]$ can reveal consistent patterns [142,143]. 
The frequency of assessment during development also affects apparent handedness. Ferre et al. [142] reported that four bimonthly longitudinal assessments from 6 to 14 months of age show a different pattern of handedness development (no significant trend in handuse preference) as compared to nine monthly assessments (a significant quadratic trend for right hand-use preference). Infant handedness is the consequence of an immature but rapidly developing nervous system that can be sensitive to different assessment procedures and conditions. Nevertheless, this does not mean that infant handedness is unreliable or even unstable or cannot be characterized.

Although questionnaires often show poor test-retest reliability [144], this can be improved psychometrically [145]. Indeed, using a psychometrically enhanced version of the EHI (and comparing it to a speed of finger-tapping performance task) and two taxometric procedures, Dragovic et al. [132] provided evidence that the distribution of hand preferences is discrete, not continuous. They found three categories of hand preference in large samples from two different geographic and demographic populations (Serbian teenagers and Australian adults): $\sim 64 \%$ with "consistent right-handedness", $29 \%$ with "inconsistent right-handedness", and 7\% with "consistent left-handedness". Hand preference was assessed using a shortened (only seven questions-drawing hand, upper hand on broom, and hand for lifting lid of a box were removed) but psychometrically enhanced EHI with better measurement properties [146].

Interestingly, one criticism of the EHI is that it is composed of actions, the majority of which are culturally dependent on Westernized tools [127]. Even a sample from a population in France had to have the broom question removed because so few participants had experience with a broom [18]. Nevertheless, the EHI is the most commonly used handedness assessment method in neuroscience research [147]. In addition, when used, it is often modified according to the purposes of the researcher, which can change its psychometric properties [147].

For example, Christman and colleagues (e.g., $[4,148])$ used neither a statistical nor a taxometric method with EHI scores to create a three-group classification procedure that distinguished "consistent right-handed", "consistent left-handed" and "inconsistent handed" (or "mixed-handed") individuals. They note that mixed-handed individuals are not ambilateral. Indeed, a "mixed-handed" individual could be someone who reports "always" using their right hand for 8 of the $10 \mathrm{EHI}$ questions and "usually" using their right hand for one activity, and "always" using their left hand for the one remaining question. Thus, the "mixed-handed" group is likely to be more heterogeneous than the "consistenthanded" groups (a dodgy problem for statistical analysis). Then, they examined different relations of mixed-handed vs. consistent-handed individuals for many psychological functions (e.g., eating disorders and body image, gullibility, false memory, framing effects in cognitive decisions, Foreign language learning, episodic memory, paranormal beliefs). Some of these psychological functions are measured by a questionnaire, but some by empirical manipulations [4].

Since mixed-handedness (albeit not defined as in the Christman studies) is reported to be associated with a larger corpus callosum and presumably facilitates interhemispheric communication, Christman and colleagues posed a particular hypothesis about hemispheric specialization of function and interhemispheric communication to account for the observed relation of handedness to so many psychological functions. Their hypothesis [4] proposes a dual process pattern of hemispheric specialization with some psychological functions requiring mutually exclusive separation between hemispheres (e.g., the left hemisphere efficiently processes prototyped/abstract visual forms, whereas the right hemisphere efficiently processes exemplar/specific visual forms) and other functions require interhemispheric integration for effective functioning.

By re-examining several of their experiments, they [4] discovered that when dual processes must be integrated, mixed-handers are more affected by the experimental manipulations; whereas, if the processes are mutually exclusive (independent), then it is consistent right-handers who are more affected by the experimental manipulations. Christman and 
colleagues do note that the hemispheric specialization of some functions for consistent lefthanded individuals is distinctly different from that of consistent right-handed individuals, but since consistent left-handers are such a small proportion of the population ( $2-3 \%$ by their method of classifying handedness), they are considered too difficult to study and were ignored in the analyses ([4], footnote p. 3).

So, in order to reveal a relation of handedness to a very large variety of psychological functions, Christman and colleagues propose an elaborate theory about the relation of types of handedness (consistent right-handedness vs. mixed) to hemispheric specialization and interhemispheric communication. To derive the consistent verses mixed-handedness groups, they manipulate the EHI by using the absolute value of the LI scores, identifying the median (supposedly a score of 80), and then classifying individuals with absolute value scores of 75 or less as mixed-handed and those with higher scores as "consistenthanded". Using the median to construct groups is statistically troublesome, at best. At least, the classification technique of Dragovic et al. [132] might have been a more defensible procedure for specifying handedness groups. Even so, I would argue that the Christman method is not an adequate means of defining handedness groups, especially from the EHI scores. Therefore, the relation of handedness to such a variety of psychological functions needs replication and evaluation using more defensible ways of characterizing types of handedness. Indeed, I would apply this concern to nearly all studies that use questionnaire data to relate handedness to other psychological functions.

A third method of assessing handedness derives from observing preferred hand use during various manual actions. This reveals even more individual variability than the questionnaire assessment, probably because the self-report is biased by the individual's narrative identity and their desire to create cognitive consistency. In addition, the questionnaire may miss some aspects of manipulation that commonly occur in daily activities (self-grooming, gesturing, pulling/pushing oneself up from squatting, etc.). Observed handedness ought to bear some relation to hand differences in the gestural actions of infants and children (but see $[149,150])$. In addition, unless statistical procedures are used to reveal underlying groups of individuals with different patterns of hand-use expression [151], the variability is likely to be more continuously distributed among the members of the population.

The fourth assessment method examines differences between the hands in actual skilled activities. The measures include speed and accuracy differences between the hands or perhaps differences in leaning trials. There are various elements that make up manual skill, such as grip strength, finger dexterity, sequencing ability, and coordination across muscles, fingers, and hands. Each of these can be assessed by different functional tasks [152]. These measures can produce more precise descriptions of individual variability of handskill differences. Of course, this fourth method is affected by hand preference differences, which can lead to practice differences between each hand. Thus, skill differences have to be assessed with tasks that bear little resemblance to more highly practiced common manual actions (originally derived from hand-use preferences) with the hope that there are no simple transfer effects from the highly practiced actions to the relatively novel actions. Novel tasks are believed to identify the underlying processing differences between the hemispheres that produce the functional differences of handedness. However, even moving pegs from one set of holes to another nearby set likely involves transferred skills from other manual actions of grasping, relocating, and releasing an object. Perhaps that is why a GWAS and Annett's peg-moving task with over 2500 children and parents found that no SNP was associated with relative hand skill [82].

This fourth method ought to provide insight into the organization of the neural circuits that control different kinds of manual actions (e.g., finely-timed, serially ordered motor control of finger movements versus finely-timed, serially ordered motor control of shoulder, elbow, and wrist movements, or visually guided actions versus more ballistic or proprioceptive-guided actions). In addition, the assessments from this fourth method ought to correlate with praxis in neuropsychological functioning. Although the preferred hand 
is generally more skilled at performance-based tasks than the nonpreferred hand [153], McManus et al. [125] argue that measurements of performance, rather than reported preference, ought to be relied upon when investigating hemispheric specialization of function. Performance tasks likely tap into the neural mechanisms underlying lateralization of functions.

Several studies have used performance-based measures of preference, such as midline crossing tasks (e.g., [154]), to assess handedness. Midline crossing tasks measure the point at which reaching across the midline into contralateral (i.e., opposite) space with the preferred hand becomes too awkward, and participants switch to the nonpreferred hand to complete the task. Unfortunately, there is no agreed-upon set of novel tasks to measure the different aspects of hand differences in skill nor agreement on how to combine the speed and accuracy differences between the hands across tasks to create a general manual difference score. Moreover, since such performance tasks require the participant's comprehension of instructions and a motivation to perform the task as quickly and accurately as possible, this method is not appropriate for studying handedness development during infancy and early childhood. Finally, to date, this method has not incorporated any measure of RDBM (but see [155]), which may be the most important component of the expression of human handedness because so much of historical and even current tool manufacture and tool-using skills involve RDBM actions (e.g., [156]; see also, [157] about RDBM in professional musicians).

Comparison across each of these four methods of assessment results in too many individuals being classified differently $[125,144]$. A self-identified right-hander may become a weak left-hander by questionnaire, observed preference for use, or in measures of the differences in skill between the hands. Therefore, it is not surprising that across studies, there would be differences in the association of handedness with other forms of hemispheric specialization. Indeed, some conclude (e.g., [95]) that genetic and neuroimaging studies in human adults have failed to support any causal relation between the direction of handedness and the lateralization of language. However, most studies assessing hemispheric specialization of function still use self-identity (sometimes checked by writing hand) or a questionnaire (most often the EHI) to assess handedness [147].

In the largest meta-analysis of handedness to date (over 2 million participants), Papadatou-Pastou et al. [158] converted each participant's handedness into a classification of Right-Mixed-Left (R-M-L), Right-Left (R-L), and Right-nonRight (R-nonR) in order to estimate the prevalence of left-handedness in the general population. Five meta-analyses measured (1) total left-handedness (irrespective of classification scheme), (2) non-righthandedness (from R-nonR classifications), (3) left-handedness from forced choice (from R-L classifications), (4) stringent left-handedness (from R-M-L classifications), and (5) mixedhandedness (from R-M-L classifications). Moderators for the analyses included comparing different measures of handedness (EHI, Annette's, self-description, writing hand, etc.), ancestry of participants (sub-Saharan Africa, European, East Asian), response format, year of publication, education of participants, and mixed-handedness (from R-M-L classifications).

They found no evidence of relevant differences in prevalence estimates for lefthandedness based on writing hand assessment as compared to self-classification or assessment with most questionnaires. The proportion of left-handedness was found to be about $17 \%$ for nonR-R classification schemes, $10 \%$ for R-L classifications, and 9\% for R-M-L classifications. Mixed-handedness also represented about $9 \%$ of the population. Ancestry affected the prevalence of left-handedness, with Europeans having the greater proportion $(11 \%)$. Males were consistently more likely to be left-handed than females, and increased education increased left-handedness. The authors conclude that a shorter questionnaire or even writing hand can be used to assess handedness. In contrast, I would argue that questionnaires are not adequate means for assessing handedness if the intent is to relate handedness to sensorimotor control mechanisms.

A recent study [125] compared performance differences between hands using the Tapley and Bryden task (TBT) of dotting inside sequences of "Os" and the Annett pegboard 
task (APT) and related these performance differences to the scores on a modified EHI and self-described handedness. When classified into groups, the distribution of LI scores on the mEDI was highly correlated with self-described handedness. I would interpret this result as the need of adult subjects to make their questionnaire answers consistent with the narrative identity of their handedness. McManus et al. [125] also reported that despite the $\mathrm{T}$ and $\mathrm{B}$ performance task being a very suitable measure of direction ( $\mathrm{R}$ or $\mathrm{L}$ ) of handedness, it is not a suitable measure of the degree of handedness. They conclude that the differences between left- and right-handers versus those differences between strong and weak lefthanders (or strong and weak right-handers) are the result of the processes from different underlying mechanisms. As yet, there is no evidence for these different mechanisms.

However, it is likely that the neural mechanisms associated with controlling the sensorimotor skills involved with the actions that create handedness differences in performance or preference for use are different from those associated with self-identity or languagedependent questionnaire accounts of handedness, both of which depend upon declarative memory. I would argue that the neural mechanisms associated with identity and self-report assessments would bear little relation to those associated with the production of speech (a sensorimotor process that is more similar to the control of the hands). Therefore, I would not expect identity handedness to be related to measures of speech production and decoding.

Hickok and colleagues $[44,159,160]$ also argue that the neural circuits involved in speech production and decoding are different from those involved with processing the conceptual-semantic aspects of speech. They propose that the processes used to produce speech (and decode it before subsequent semantic analysis) are associated with circuits that are involved with other sensorimotor processes. Indeed, there appear to be neural circuits that support the interface between auditory and motor processing of speech similar to those involved with sensory-motor integration. These supramotor functions (e.g., sequencing actions and the precise timing of muscle contractions and relaxations) are not specific to speech but underlie all action preparation [161].

Many models of speech motor planning propose that speech derives from common action control and motor-sequencing mechanisms that also underlie many other cognitive processes $[162,163]$. Therefore, the neural organization of speech production is likely to overlap with those motor control regions likely involved with manual differences in those skills associated with handedness. For example, Broca's area is associated with many nonlanguage motor functions, including planning actions, imitating actions, and using tools $[164,165]$. Therefore, if handedness is to be related to hemispheric specialization for speech production, we need to focus on differences in hand preference or skill, not narrative identity or questionnaire scores [19]. For example, Packheiser et al. [20] found no association between lateralization for language (as measured by ear differences in dichotic listening) and handedness for over 1500 adults. Handedness was measured by the EHI using four common classification schemes, including one based on latent class analysis.

The sequencing of speech motor acts and the organizing of segmental information into words and sentences prior to vocalizing relies more heavily on the motor areas. Interruption of these motor regions via transcranial magnetic stimulation (TMS) has been shown to disrupt sequencing actions on a finger-tapping task and to impair the performance of oral motor gestures [166]. Such results suggest that the cortical organization of motor and speech networks may be complementary [167]. Studies also show a clear role for the cerebellum and basal ganglia in translating motor planning into action for speech and manual actions [163], and deficits in cerebellar-parietal networks occur in children with developmental coordination disorder (DCD-[168]). Therefore, to understand the manifestation of handedness, it is important to understand the neuroscience of forelimb movements.

\section{The Neuroscience of Arm/Hand Control}

Bizzi and colleagues (e.g., [169]), using research with mice and monkeys, have proposed a sensorimotor feedback loop perspective for understanding the control of the arms 
and hands in humans. There are multiple sensorimotor loops involving various areas of the cortex, other brain regions, the spinal cord, and the sensorimotor periphery, all of which influence the cortical motor output regions. They argue that the continuous convergence of these loop activities at the cortical output regions somehow results in the emergence of functionally appropriate movement commands. Thus, supraspinal control of spinal corddependent motor action emerges as a result of multiple sensorimotor loops converging on the motor cortex (of course, there are other supraspinal projections to the spinal cord that contribute to the production of movement and the maintenance of posture).

The spinal cord produces motor actions (muscle movements) via motoneurons in the ventral horn that project directly to muscle cells. In addition, interneurons in the cord form connections with multiple motoneurons. The activity patterns of interneuronal connections among motoneurons operate as action circuits or "muscle synergies" [169], coordinating muscle contractions and relaxations. The "memory" (likely via synaptic processes) of forces stored in these action circuits in the spinal cord represent motor primitives from which many movements can be formed via the imposition of neural impulses from supraspinal tracts. By differentially combining this relatively small set of muscle synergies, via supraspinal variations in the timing and sequence of their activity, the CNS can create a wide diversity of actions that likely are only constrained by the biomechanics of the skeletal-muscle system and the conditions of the task and context [104].

Thus, the same spinal muscle synergy may be used in a variety of actions, and different actions may be constructed from the same set of synergies by altering their timing and scaling factors. The development of new skills can lead to the formation of new specialized task synergies [170], but these may involve cortical sensorimotor loops creating synergies in primary motor cortical cells (M1) and dorsal premotor cortical cells (PMd).

There is some evidence that the synergies in the spinal cord of 5-day-old rats do not change further during development [171]. However, the life of a lab rat is not particularly complex, nor does it require adjustments to a changing environment. Therefore, developmental psychobiologists Robinson, Brumley, and colleagues have demonstrated that from embryonic day 19 through postnatal day 7, the fetal and young rat pup is capable of learning new and unusual coordinative patterns of limb activity that likely involve new spinal synergies created by sensory feedback [172-178]. Therefore, it is quite likely that the synergies established in the prenatal spinal cord are influenced during their development by feedback from the spontaneous myogenic and neuromotor activity of the fetus and newborn. Any lateral asymmetries in such feedback would impose asymmetries in the spinal synergies [52].

During movements, the muscle synergies together with their muscle spindles, joint, and skin receptors generate a flow of diverse sensory signals that provide feedback to the establishment and maintenance of the synergies. These sensory signals, by way of multiple ascending pathways, provide the M1 and PMd cortical cells with the feedback that contributes to the regulation of these cells as they activate the movement that permits conformance to the external world. Thus, any lateral asymmetries in spinal synergies could influence the development of lateral asymmetries in cortical motor mechanisms.

Bizzi's sensorimotor loop perspective argues that all movement involves a continuous interplay between system inputs/outputs and behavioral "predictions" / realizations [179]. Effective functioning of arm/hand actions needs simultaneous feedback of position, velocity, and force information for modulating effective performance in the event of possible perturbations. In adult humans, the M1 and PMd cells become active during preparation for movement. They also become active when thinking about performing an action or observing others perform the action.

Besides activating the muscles for the performance of an action, the motor system must anticipate and cope with movement-related challenges (postural adjustments to maintain stability during action, inhibition of antagonistic muscles for the action, setting of expected gains in afferent sensations, and the processing of corollary discharge signals). Thus, among the array of sensorimotor loops that involve the motor regions of the cortex 
are the frontal-parietal (F-P) loops, the thalamic (T) loops, the basal ganglia (BG) loops, and the cerebellar (C-C) loops. The onset of neural activity in the cortical motor areas is followed by neural activity in the putamen and cerebellum, indicating that the basal ganglia and cerebellum may receive an efference copy of the M1 and PMd activity state. The BG loops seem to be involved in habit and skill formation by organizing motor actions into chunks [180], and several loops seem to possess sub-movements that could be combined to form more complex movements.

The cerebellum seems to provide continuous adjustments to motor output based on the inflow of the system's state. Neural signals from the thalamus, sensory cortical areas, basal ganglia, and cerebellum converge on M1 and PMd neurons and the secondary motor area (SMA, which is involved in motor sequence learning), the cingulate motor area, and area 5. These, in turn, also form loops with M1 and PMd. The convergence of these inputs mobilizes the pyramidal tract neurons of M1 and PMd, into forming time-varying control signals sent to spinal cord interneurons and motoneurons to activate spinal synergies. Although the patterns of activity for individual fingers seem to be organized in M1, the population-level activity of PMd is involved in the production of sequentially organized finger movements [181].

The spinal motor neurons innervating the distal muscles of the forelimb (wrist and hand) receive more monosynaptic cortico-motoneuronal projections from the M1 and $\mathrm{PMd}$ regions than those controlling the proximal muscles innervating the shoulder and elbow $[182,183]$. This means that there is more cortical control of the action of the motor neurons that enable more precisely timed, sequentially organized movement of the wrist and fingers of the hand. Since such fine motor actions of the hand depend upon such direct projections from the contralateral M1 motor cortex (e.g., [184]), these differences in cortical control become important when trying to determine the neural mechanisms of handedness [72]. Moreover, such information shows why questionnaire assessments of handedness may not be very revealing of those neural mechanisms that also might be employed in other lateralized functions such as speech production and decoding (cf., $[185,186])$.

A wide range of subtrajectories or movement fragments seems to be represented in M1. These fragments are thought to be controlled by the different classes of motor cortical cells, which raises the question of how the supraspinal system manages to recruit the synergies in the correct spatiotemporal pattern to effectively control movement. Given the presence of so many sensorimotor loops, it seems clear that there is no single controlling mechanism, but rather, control emerges from a highly distributed scheme. In addition, it seems likely that differential experience in moving the forelimbs (i.e., feedback via spontaneous actions, practice, or learning) can contribute to differences in the mechanisms of control, and these differences can have wide-ranging consequences on brain structures other than the motor cortex and its direct loops. My perspective on handedness development incorporates the consequences of such feedback for the organization of the mechanisms of handedness [24,46,187].

A review of studies of individuals who had to change their handedness because of injuries [76] revealed that those neural asymmetries related to handedness are a consequence of the lateralized practice induced by the change in hand-use. In addition, musical training in left-handed individuals is related to atypical language dominance [188]. Nicolini, Harasym, Turco, and Nelson [75] provide some problematic evidence that human motor cortical organization is influenced by handedness (as measured by EHI but without noting handedness cut-point scores). Despite the extensive evidence for sensorimotor loops between the motor cortex and cerebellum and the role of the right cerebellar hemisphere (contralaterally connected to the left cerebrum) in language expression [189], studies fail to reveal any relation of handedness to cerebellar structure/functions [190,191]. However, Kavaklioglu et al. [190] assessed handedness via a dichotomous selection item on a form, and Polat [191] used a French version of the EHI. Neither assessment is acceptable for evaluating hand differences in sensorimotor abilities. 
The complexity of the loop system involved with manual actions makes it likely that some of the sensorimotor loops that are involved with handedness could be used in the control of other complex movements such as speech acts and their decoding. Hodgson and Hudson [192-195] argue that a specialized speech-praxis computational network exists in the left hemisphere, which specializes in processing phonological and auditory information, planning and controlling motor actions, as well as, controlling the sequential character of complex "higher-order" operations. They also propose that individuals who display atypical handedness or right-hemisphere speech must use the callosal pathway to access this speech-praxis network. Thus, the connectivity between the hemispheres becomes more integral to successful functioning in atypically lateralized individuals because intrahemispheric networking within the right hemisphere is presumed to be poorer and operationally less effective [193].

Left-handed individuals would have to use the corpus callosum (CC) to access the proposed left-hemisphere speech-praxis network in order to control their left hand. Of course, this notion presumes that there is some sort of intrinsic left-hemisphere speech-praxis network that is established early in development, independently of the feedback experiences provided by prenatal and postnatal differences in hand-use. The work of Robinson and Brumley makes that unlikely. However, even for typically lateralized individuals, the CC may play a pivotal role in the development of left-hemisphere specialization for language [196].

\section{Interhemispheric Communication and Coordination}

The corpus callosum (CC) is considered to be the primary mechanism for coordinating the two hemispheres, especially for integrating the complementary processes of those functions that differ between the cortices. Investigations on callosotomized patients revealed many of the different functions of the two hemispheres and the role of CC in the coordination between them (cf., [197]). The CC is believed to inhibit the actions of one hemisphere as the other engages in processes that would be compromised if both hemispheres were simultaneously active. In addition, the CC is believed to use sequential inhibition/activation to create collaborative functions involving contributions from both hemispheres.

Partial callosotomy has shown that CC is topographically organized with the splenium involved with the transfer of visual, auditory, and somatosensory information and more anterior regions involved with the transfer of attentional resources and higher cognitive information [196]. The CC contains both small diameter fibers, typically providing inhibitory consequences (likely via activation of GABAergic interneurons within the receiving hemisphere) across secondary multimodal associative areas, and large fast-conducting fibers providing excitatory connections on primary and unimodal associative areas. Thus, it is difficult to infer the CC role simply from gross anatomical variables, and many investigations have used some parcellation scheme (e.g., [198]).

Bimanual coordination of sensorimotor skills and the intermanual transfer of tactile (haptic) experience are considered suitable behavioral indicators of interhemispheric communication. Anatomical evidence suggests that much of the sensory and motor innervation of the hands and fingers in humans is restricted to the contralateral cerebral hemisphere. However, some cortical neurons do have both ipsilateral and contralateral connections with the hands and fingers [199]. This means that some ascending information from sensory receptors in the hands has ipsilateral as well as crossed projections to the cortical hemispheres, and some descending activity of each cortex has both ipsilateral and crossed influence on the hands and fingers. Nevertheless, for many aspects of fine motor control and more sophisticated haptic perception (especially in adults), the hemispheres possess primarily a contralateral relation with the hands. Unfortunately, there is too little research examining the development of the contralateral and ipsilateral factors coordinating the two hands (hemispheres) for action and perception. 
Evidence from callosotomized adult monkeys and humans shows that the corpus callosum is involved in the intermanual (interhemispheric) transfer of certain sorts of haptic perception and for the control of certain kinds of bimanual skills [200-203]. Although each hemisphere seems capable of monitoring proprioceptive information from both sides of the body (likely via extralemniscal and spinal-thalamic ipsilateral pathways), callosotomized patients seem to be unable to mimic with one hand the postures imposed on the fingers of the other hand, nor are they able to retrieve with one hand an object from an array that matches an object held in the other hand [203]. In addition, familiar bimanual tasks involving interlimb coordination of simultaneous actions of the hands can be performed after callosotomy, but novel tasks involving asymmetric but synchronous actions cannot be $[200,201,204]$. Thus, in the absence of callosally mediated interhemispheric communication, certain forms of haptic experience and manual skill may be restricted to one hemisphere. However, this restriction derives from a small sample of adults whose brains have had years to decades of intractable epileptic seizures before undergoing callosotomy.

Notably, in a small sample of five callosotomized children (to control seizures), the three that were callosotomized before 10-years-of-age exhibited little effect of callosotomy $[205,206]$. Such young children are capable of naming shapes in their non-dominant hands, and they exhibit intermanual transfer nearly immediately post-operation. To account for these minimal postoperative deficits, some functions of the immature CC must be shared with alternative pathways, most likely the proprioceptive feedback provided by the ipsilateral extralemniscal and spinal-thalamic pathways. Moreover, some children callosotomized after age 10 but before mid-adolescence recovered from their interhemispheric dysfunctions, unlike adults. Thus, continued development must lead to the cortex rewiring through the elimination of overproduced connections [207], perhaps via experience and learning [208,209]. Clearly, such results indicate that the functional development of the CC needs more extensive investigation [2].

Although some evidence suggests that the corpus callosum does not exhibit anatomical or physiological maturity until the end of the first postnatal decade $[210,211]$ and perhaps as late as the third decade [212], the contribution of the corpus callosum to behavioral development has not been examined systematically [2]. Anatomically, there are many late gestational and early postnatal changes in the CC involving axonal elimination and redirection (cf., [212]). Myelination of the CC begins about 3-4 months postnatally and continues well into adulthood. EEG data suggest the synchronization of cortical pre- and post-synaptic activity begins in 7- to 12-month-old infants [213]. Farber and Knyazeva [214] reported that interhemispheric synchronization rapidly increased between 2 to 7 years of age, but the rate of increase slowed progressively from middle childhood to adolescence (17 years). It is likely that the relatively low level of functional cooperation between hemispheres in the young brain means that local intrahemispheric mechanisms underlie most functioning in early childhood [212].

The primary sensory and motor areas of the cortex subserving the hands mature rather early in infancy [215], but these areas are callosally connected only indirectly via "association" cortex with the opposite hemisphere [216]. Thus, the sensorimotor cortical areas must establish connections within a hemisphere with those association cortical areas in order for the callosum to subserve interhemispheric coordination for the hands. These other cortical areas are involved with the processing of multimodal sensorimotor information involving the hands [217], and they reach anatomical and physiological maturity later in infancy [215]. Therefore, certain forms of intermanual transfer of haptic information and bimanual coordination may be developmentally delayed by normal immaturity of parietal and frontal "association" areas as well as the immaturity of the corpus callosum. The feedback provided by a hand-use preference during this phase of development would likely affect the development of the pattern of sensorimotor loop mechanisms within each hemisphere.

The degree of interhemispheric communication could be measured by assessing the inter-haptic perceptual abilities and intermanual skills of infants and children during the 
period of callosal immaturity. Thus, Streri and colleagues (cf., [218]), beginning in the mid1980s, demonstrated intermanual transfer of haptic discrimination of object contours (prism vs. cylinder) not just in newborn infants and very young infants but also in premature infants as early as 28 weeks gestational age [219]. In all publications, the testing occurred during the infant's calm alert state and with very minimal loss of infants as a consequence of state changes or other factors $(<5 \%)$.

Streri and colleagues used a haptic discrimination task that involved the presentation of a cylinder-like object versus a prism-like object placed in the hands and recording time to drop the object. Repeated presentations of the same object (e.g., cylinder) resulted in more rapid dropping, which did not happen if a novel object (prism) was presented (the novel object was held longer). Streri observed that habituation to the repeated presentation of one object (e.g., cylinder) for the tested hand was transferred to the initially non-tested hand. Since recovery from habituation (e.g., presenting the novel prism) was demonstrated for both hands, CC functioning was presumed to be present even in premature infants. Interestingly, Lassonde et al. [206] warned that proprioceptive feedback for haptic stimuli that relied upon angularity and curvature could be carried via ipsilateral mechanisms. Thus, assessing interhemispheric communication via intermanual transfer of haptic information depends upon the stimuli used. Since my perspective on handedness development involves a relative independence of the hemispheres early in development, I would welcome independent replication of the results of Streri and colleagues.

Before the publication of Streri's early work, we had used a head-turn conditioning procedure to assess the intermanual (interhemispheric) transfer of learned haptic discrimination (unpublished but see [220]) by 35 7- to 14-month-old infants. Two stimuli differing only in texture (rough vs. smooth-in order to avoid ipsilateral proprioceptive feedback) were presented singly to the right hand of the infants in a semi-random pattern. During the presentation of each stimulus, an assistant appeared to the left- or right-side of the infant and played peek-a-boo. Each texture signaled the direction (right or left) from which the assistant would appear. An overhead video camera recorded the direction of the infant's head turns during the stimulus presentation periods but before the appearance of the assistant. Directionally appropriate head turns for four consecutive stimulus presentations defined discrimination learning.

Only seven infants (one each at 10 and 12 months of age; the remaining five were over 12 months) learned the discrimination. After learning, intermanual transfer was assessed by presenting the stimuli four times to the left (untrained) hand without reinforcement. None of the seven infants showed any evidence of transfer; however, each showed correct head-turning (without reinforcement) when the stimuli again were presented to the trained right hand. Although only preliminary and subject to concerns about the ease of learning the task, these data suggest that the callosum may not transfer certain learned sensorimotor experiences between the hemispheres during the infant's first year. Since infants establish hand-use preferences for reaching and object manipulation in their first year, and if they cannot transfer certain learned tactile discriminations intermanually, then the preferred hand is likely to establish a more haptic experience and to have engaged in more actions with objects than the nonpreferred hand.

The potential absence of interhemispheric transfer during a period of early hand preference for manipulation of objects would mean that the infant's haptic experiences with the preferred hand would be restricted to the contralateral hemisphere and not shared with the relatively naive hand/hemisphere. Theoretically, the supraspinal sensorimotor loops involved with control of the preferred hand, along with the corresponding spinal synergies, would have a different pattern of feedback than those involved with control of the nonpreferred hand. Thus, early differences in hand use could play an important role in the organization of the nervous system [187,221].

Trevarthen [222,223] showed that for adult monkeys, who previous to the surgery have learned a complex RDBM skill (in which each hand must perform separate actions), callosotomy did not affect the sequential unimanual performance of the skill when the 
RDBM action is prevented by restricting the use of one hand. That is, during the visuomotor learning of the RDBM skill, the information was shared between hemispheres so that each hemisphere retained the sequence needed for the manifestation of the skill. In contrast, for callosotomized monkeys (lacking interhemispheric communication) who learned the RDBM skill, only the hemisphere that is actively controlling the actions of the hand involved in learning its part of an RDBM skill (i.e., the hemisphere contralateral to the performing hand) will incorporate the visual information produced by these actions into the visually coordinated sensorimotor schemes needed to do the task. When the RDBM action is prevented by restricting the use of one hand in these callosotomized monkeys, they could not perform the skill sequentially. Thus, the callosum is important for the interhemispheric transfer of certain visually controlled manual skills during their acquisition. Trevarthen's studies [222,223] show that callosotomy permits different sensorimotor skills to be established separately in each hemisphere, even when both hemispheres have visual information of the performance of each hand.

If callosal functioning is limited during the period of infancy (e.g., [224]), when handuse preferences in object play are prominent, then the sensorimotor skills created in play could be restricted to the hemisphere contralateral to the playing hand, even though visual information about the skills are available to both hemispheres. When both hands engage in manipulatory play, the action differences induced by a hand-use preference will result in the establishment of different sensorimotor schemes or loops in each hemisphere.

Of course, there are many ways whereby the two hemispheres may share information [2]. There are subcortical systems (involving the cerebellum, basal ganglia, and superior colliculus) that project between the hemispheres and operate in interhemispheric coordination. In addition, manual actions are not completely lateralized. There is bilateral control of the shoulder and upper arm, and this can play an important role in RDBM. Moreover, functional systems that may be isolated within a hemisphere can have time during development to acquire subtle cues for communication and coordination that need not rely on neural connections between the hemispheres. Feedback of various sorts from facial muscles, eye movements, postural shifts, etc., can provide rather reliable information transfer between hemispheres [225]. These may account for the lack of a disconnection syndrome in children with early callosotomy.

Thus, the issue of interhemispheric coordination is complex, involving many neural mechanisms beyond the CC. Current theories about such coordination are too simple and restrictive (most often to the CC) to likely be informative about the development of handedness or other forms of hemispheric specialization. Nevertheless, it is very likely that interhemispheric coordination (perhaps, via different mechanisms at different phases in development) plays an important role in hemispheric specialization. For example, young children exhibit a number of unintended synergies during fine motor movements of the hands and fingers, which interfere with intermanual coordination in motor skill $[226,227]$. These unintended cross-manual synergies (sometimes called mirror movements or associated movements) decline with age, and the synergies have been proposed to represent immature callosal functioning [228,229]. Interestingly, only during the second half of their first year do infants exhibit bimanual coordination of the movements of their arms and hands [230]. Since such coordination likely relies on the CC [231], we [232] used a large object to reliably elicit bimanual reaching during this age period.

Although both 7- and 11-month-old infants showed the same frequency of bimanual reaching, the spatial coordination and temporal coordination of their arm movements were not the same. For 7-month-old infants, the timing of the movements of each arm was more tightly linked to that of the other arm than for 11-month-old infants. Moreover, at 7 months, the direction of each arm's movements matched the direction of the other arm's movements. That is, if one arm moved to the right, the other moved to the right at the same time. At 11 months, the hands converged on the target (i.e., when one arm moved to the right, the other moved to the left, etc.), with greater independence in the timing of each arm's movements. 
It is not known whether one hemisphere is controlling the spatial and temporal coordination of the movements of both arms during bimanual reaching at 7 months. However, a hand-use preference does affect the pattern of coordination during bimanual reaching both when there is a minor impediment (low barrier) in the path of either hand and when there is no impediment [233]. For those infants with a hand-use preference, the impediment disrupted the pattern of bimanual reaching in 7- and 8-month-old infants but not in 11-month-old infants. The younger infants were more likely to hit the barrier when it was in the path of their nonpreferred hands but not when it was in the path of their preferred hand.

If bimanual reaching was controlled by one hemisphere in the younger infants, with bimanual coordination achieved by simultaneous contralateral control of the preferred hand and ipsilateral control of the nonpreferred hand, then the tight spatial and temporal linkage in the movements of each hand during bimanual reaching and the pattern of disruption of bimanual reaching caused by the presence of an impediment in the path of the nonpreferred hand might be expected. Subsequent development of more effective functioning of interhemispheric coordination would permit each hemisphere to control the spatial and temporal parameters of movement of the contralateral hand according to the requirements of the task, the actions of the other hand, and the conditions affecting its trajectory.

It is likely that the developmental changes in the coordination of bimanual reaching during the first year could reflect developmental changes in the functioning of the interhemispheric coordination [231]. Recently, no transfer of a learned sequence of finger movements was observed between unimanual and bimanual movements in adults. The authors interpreted these results to mean that the integration of both-hand sequential movements is coordinated at a different level of organization than one-hand movements [234]. Thus, knowing how haptic experience is transferred intermanually and how bimanual action is coordinated is important for understanding the development of interhemispheric collaboration.

\section{My Perspective on Development}

To many researchers, development is a process that operates during the early phases of a lifespan, and it has an endpoint (e.g., the production of an adult). The changes that occur toward the end of a typical lifespan are labeled as aging and not development. Of course, defining an adult is difficult for humans. For many animal species, an adult is that phase of the individual's lifespan during which reproduction is possible and often occurs. However, for many human cultures, the transition of puberty is not considered to be the onset of adulthood. Rather, a construct of adolescence has been created to characterize the period from the pubertal transition to some later phase of the lifespan when the individual is extended the rights, privileges, and responsibilities of adult members of that society. Of course, post-pubertal individuals are capable of reproducing, but the cultural norms may inhibit such reproduction until the individual has effectively transitioned into adulthood via some rite of passage (even if it is simply some arbitrary number of years postpartum (e.g., 18 or 21 years), as in many Western societies).

In neuroscience, human adulthood is often defined by some gross anatomical measure of the brain (e.g., the extent of myelination of cerebral axons, amount or pattern of white matter among cerebral areas, electrophysiological evidence of "adult-like" wave forms, etc.). However, even these definitions are assumed to be captured readily enough by the adoption of some conventional age marker (e.g., 21-25 years postpartum). However, myelination can continue for many years after age 25 (although most of it is completed before then), and synaptic connections can continue to rearrange themselves throughout the life span (although major reorganizations are much less likely to occur after the age of 6-7 years). Oddly, few studies focus on what factors limit or reduce the likelihood of reorganization across the lifespan; hence, the young brain is simply considered to be 
more plastic than the older brain. Therefore, development sometimes may be considered a process of reduced brain plasticity for structural and functional reorganization.

Rather than approaching developmental phenomena as directed toward some endstate (a "development to" adult-like traits approach), many developmental psychobiologists consider developmental traits to emerge from the transactions/coactions among physiological processes internal to the individual operating in collaboration with those experiences provided by the individual's context resulting in a "development from" earlier traits approach [9]. Such developmental coaction produces new traits or maintains traits at a particular level of function. Common endpoints are not ignored in a "development from" approach, but rather these do not direct the pattern of investigation. This permits the discovery of "multiple trajectories" in development that accounts for how initial differences early in the developmental pathways can lead to similarities in later phases and how initial similarities in early developmental pathways can lead to differences in later phases. The task of the researcher is to identify those factors during development that contribute toward maintaining the consistency of the individual's trajectory and those factors that contribute toward changing the trajectory (Figure 1).

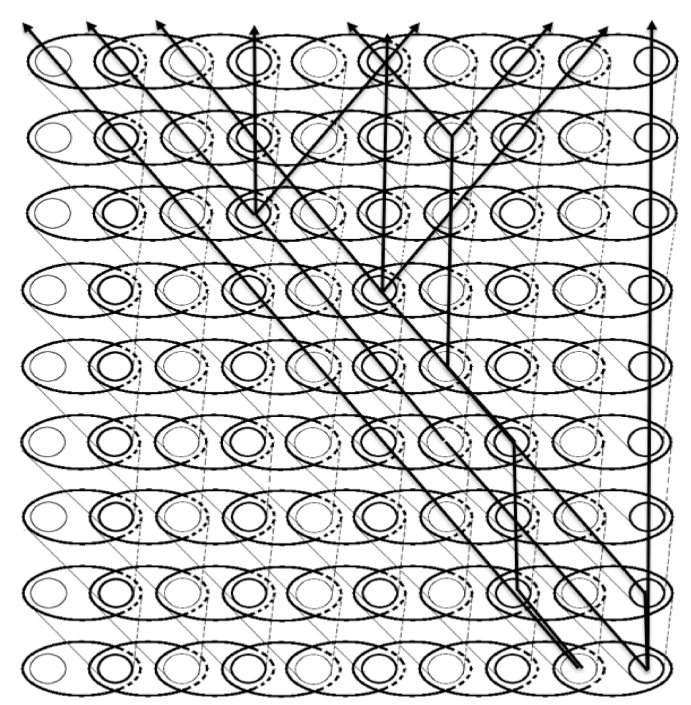

Figure 1. Development is a continuous transformation throughout the lifespan. At the lowest level of this figure, the coaction of different genomes (dark and light smaller circles) with their environments (larger ellipses) results in the manifestation of certain phenotypes (second level). At each level, the individual's physiology co-acts with the individual's environmental context to create the phenotype at the next level. Each level emerges from the individual-environment coactions of the previous levels. Trajectory analysis reveals the transitions during development that affect phenotypic development. Such analyses identify when the individual-environment coaction results in changes in trajectory, and this prompts investigations into the mechanisms for such change. When the trajectory does not change, this prompts investigations into the mechanisms that are constraining change. Copyright $\mathrm{G}$. F. Michel, 2013.

Studies (operating within a "development to" framework) that measure hand preference from early childhood to adolescence (i.e., ages 3-12) offer no consensus about the age when adult-like handedness is attained [235]. The "development from" approach examines the development of handedness throughout the lifespan as emerging from a cascade of developmental processes operating during the preceding earlier phases of the lifespan [93]. Thus, "adult-like" handedness can be examined, within this framework, as a foundation for the development of subsequent asymmetric hand actions that appear at later phases of the lifespan (e.g., [236]).

Since lifespan differences in handedness are seldom sought in neuroscience, we have a discipline that clumps people in their mid-twenties with those in their mid-fifties who, 
perhaps, have developmental differences that may increase their variability during testing. Viewing development as a "development from" orientation is different from viewing development from a "development to" orientation. If the "development from" approach was applied to more aspects of hemispheric specialization of function, the early forms of lateralized cognitive, language, and spatial abilities might be seen to cascade into different forms throughout the lifespan.

Application of the "development to" approach is common in lateralization research. Functional MRI (fMRI) studies show that those cortical regions in the left hemisphere, known to be part of the neural network for language in adults, are activated in newborns in response to hearing sentences as opposed to music [237-239]. Even premature infants as young as 28 weeks show activation of their left hemisphere when presented with speech sounds, whereas there is just general activation of both hemispheres when presented with other sounds. It is difficult to know what this information means for the development of hemispheric specialization. Dahaene-Lambertz and colleagues interpret these results as indicating that the nervous system is set to react to speech sounds even during late pregnancy. Hence, the development of hemispheric specialization must begin with a circuitry prepared for language; perhaps, derived from some sort of genetic programming. However, there may be something about the mammalian auditory system that makes speech sounds discrimination more likely than the discrimination of other sounds. Thus, Chinchillas can discriminate human speech sounds despite any evidence that their own vocal systems use such discrimination [240].

Moreover, the premature and newborn nervous system is quite different from that of even the nervous system of older infants. Until some months postnatally, those synapses using GABA as a neurotransmitter are likely to promote action potentials from postsynaptic neurons rather than inhibiting action potentials. The cortex of the neonate, albeit in a general form similar to the older cortex, is still undergoing extensive sculpting of synapses, and thousands of neurons are dying daily. Therefore, many of these studies need replication, particularly those involving fMRI. Only since 2014 have appropriate statistical and methodological changes been instituted for $\mathrm{FMRI}$ research that makes earlier studies highly suspect (cf., [40,241-243]). Moreover, it is quite difficult to obtain reliable data from very young infants and premature infants because their posture powerfully affects their movements and manual actions [221,244,245].

Finally, evidence indicates that the vestibular system develops quite early and can affect the development of the auditory cortex along with other cortical systems [246]. Since asymmetries are present quite early in vestibular development [52] and likely contribute to the development of the auditory system; perhaps, the premature and neonatal lefthemisphere activation derives from some developmental influence of the vestibular system on cortical functioning [247].

The recent application of functional connectivity magnetic resonance imaging (fcMRI) techniques to the infant, neonatal and fetal brain development is another example of the application of the "development to" approach. This fcMRI technique uses spontaneous, low-frequency $(<0.1 \mathrm{~Hz})$, coherent fluctuations in a blood oxygen level-dependent (BOLD) signal to identify connections among cerebral areas (neural networks) during a "resting state" [248]. This technique has identified an organized, baseline mode of brain activation (the default mode network-DMN) in adults and perhaps in children. In adults, fcMRI also reveals resting-state networks (RSNs) encompassing cortical and subcortical regions that seem to relate to motor function, sensation, visual and auditory stimulus processing, memory, language, and attention; all independently of variations in states of consciousness [249].

By adopting a "development to" approach, researchers have sought RSNs in full-term and preterm infants similar to those observed in adults. In neonates (and preterm infants tested at term-equivalent age), six RSNs were found in temporal, occipital, prefrontal, parietal, basal ganglia, and sensorimotor cortices, as well as a "proto" DMN [250]. Indeed, the proto DMN has been reported for the mid-gestation fetus via in utero fcMRI scan- 
ning [250]. Since the posterior cingulate cortex (PCC) is an important component of the adult DMN and seems to be a central "hub" in brain connectivity in infants, intrauterine establishment of PCC connectivity has been claimed to be foundational to the emergent architecture of the developing human brain [250]. Other fcMRI data suggest that the fetal brain exhibits a modular organization and these modules comprise areas that will later support vision, movement, language, and data integration. Thus, the "development to" approach apparently has discovered proto RSNs, characteristic of adults and children, in neonatal and preterm infants.

Although the application of fcMRI enables assessment of the earliest forms of likely functional connectivity, fcMRI has several technical problems that apply not only to studies of adults (e.g., RSN nonstationarity) but especially to newborns or preterm infants (e.g., level of arousal and movement artifacts, [248]). For example, the most common techniques for identifying spatial patterns in BOLD activity are seed correlation analysis (SCA) and independent component analysis (ICA). SCA involves correlating the activity of a particular region with all other regions of the brain and involves a priori assumptions about the regions of interest (ROIs). ICA statistically reduces data sets to maximally independent components based upon the signal intensity time course of spatial maps (and these along with the definition of intensity must be specified, a priori). For each technique, these and other a priori assumptions are derived from studies of adults. Subtle differences in methodology at many steps in the collection and analysis of data have been reported to profoundly affect results $[248,251]$.

For example, the BOLD signal has not been adequately calculated to establish standardized values for identifying significant differences in the signal that would be relevant for neonate and infant brains, much less for preterm and intrauterine brains. Therefore, arbitrary thresholds are used. In addition, magnitude measures of the correlation thresholds are selected arbitrarily. The impact of brain development on the BOLD signal is unknown, and test-retest reliability of fcMRI results (pertinent to the establishment of normal limits) has not yet been established for different ages. Consequently, adequate fetal and neonatal templates and atlases for analysis of fMRI data are missing. Thus, apparent similarities of phenomena across age inspire speculations about proto traits that will develop into the adult traits without indicating the role that those early proto traits play in the functioning of the young individual nor in whether the proto trait is empirically related to the adult trait by processes other than similarity.

The "development to" approach can lead to potentially misleading conclusions. Using development to approach the study of handedness development, Hepper and colleagues examined one-time, brief $(<10 \mathrm{~min}$ ) ultrasound recordings collected from a large number of pregnant women (as part of the standard prenatal exam) to conclude that the formation of handedness takes place prenatally. By 10 weeks gestation, ultrasound recording seemed to show that $75 \%$ of fetuses moved their right arm more frequently than their left and $13 \%$ moved their left arm more frequently [252]. At 15 weeks, the majority of fetuses had their right thumb in their mouth [253], and this right thumb bias was correlated with their handedness (as reported by parents) at 4 years [254]. Because the fetal manual asymmetry was related to childhood right-handedness, many consider it to be early hemispheric specialization for handedness.

Unfortunately, these differences in fetal lateralized thumb sucking and arm movements were not independently confirmed by a systematic ultrasound study involving weekly longitudinal imaging of 10 fetuses scanned for over an hour each visit [255]. The longer scans from de Vries et al. permitted the collection of information on the direction of the ultrasound pulser and receiver and the position of the fetus. This information is necessary because, at the time of these studies, the ultrasound image was like a slice through a 3D object and not like the flattened image of a 3D object to a 2D picture. To interpret the position of the limbs relative to body parts required the type of precise information provided by the de Vries et al. study. Since Hepper's studies have influenced investigations 
of the epigenetic regulation of lateralized fetal spinal gene expression [256], modern "3D" ultrasound should be used to replicate the Hepper studies.

For studies of handedness, the "development from" approach does not seek evidence of handedness in the fetus but rather examines the fetus and its processes to determine how those combine with the conditions prevalent in utero to produce the hand-use asymmetries of the neonate. Then, what factors during the neonatal phase contribute toward maintaining or changing the developmental trajectory of such asymmetries. Since neonatal hand-action preferences are not homologous with those of older infants and toddlers, these should not be considered evidence of adult-like handedness (even if there are similarities of the proportion of right and left preference distributions or if there is a correlation with childhood handedness identity as reported by parents). Rather, lateral differences in fetal forelimb actions should be examined for how they might contribute to the development of later hand-use preferences and so on. Do these early asymmetries contribute to the developmental scaffolding needed to achieve the pattern of "adult" lateralization?

\section{My Perspective on the Development of Handedness}

After decades of research using the "development from" approach, I proposed that the trajectory of handedness development during infancy [24] reflects a complex cascade of contingencies involving prenatally influenced congenital postural asymmetries that contribute to the establishment of early infant sensorimotor asymmetries of arm and hand actions (Figure 2). These lateral asymmetries, in turn, promote hand-use preferences initially for acquiring objects and eventually for RDBM, construction skills, and tool use by the individual's second year postpartum $[25,93]$. In addition, handedness for RDBM during the toddler period (18-30 months) likely cascades into the development of handedness in skill differences that begin to appear in the preschool period.

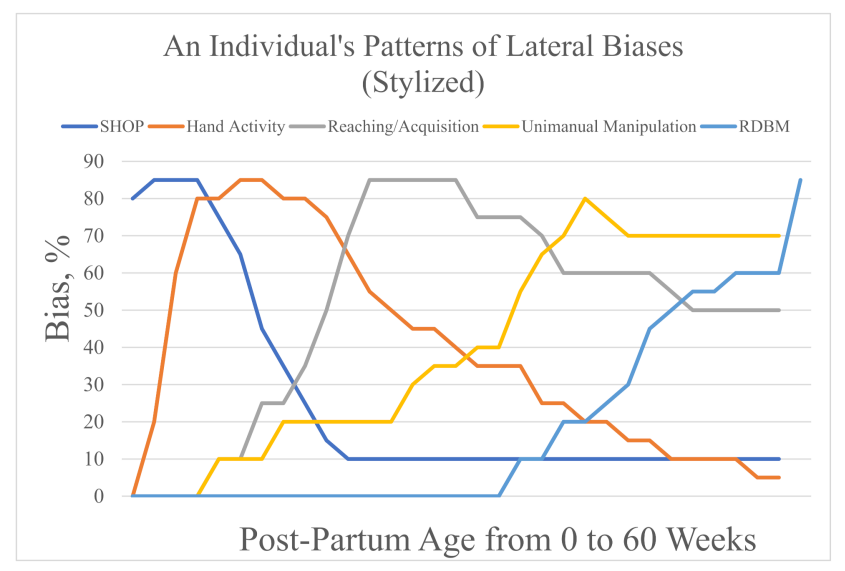

Figure 2. A stylized version of an individual's development of laterally asymmetric biases from birth to 60 weeks of age beginning with the neonatal supine head orientation preference (SHOP). Copyright G. F. Michel, 2018.

The asymmetries, throughout the trajectory, interact with the caregiver's handedness (whose handedness also is a result of the caregiver's development within a specific cultural context) to further shape the individual's hand use so that by 18-24 months, most children have a hand-use preference across a range of manual skills that are the basis of all hand actions. I also proposed that the origin of handedness need not reside in the prenatal differences in hand or limb use but rather may reside in some other asymmetrical biases, such as fetal posture and position, that would affect lateralized asymmetries in control of the arms and hands.

The neonate's postural preference reflects its prenatal posture [257] because the intrauterine position contributes to the organization of postnatal posture and "reflexes" $[258,259]$. After the 16th week of pregnancy (the period when corticospinal neurons begin to project into the spinal cord [260]), the size, shape, and specific grav- 
ity of the fetus combine with the shape of the uterus, sigmoid colon, and pelvic ring to restrict movement and position of the fetus in the uterus. The most prevalent uterine position is the left vertex that places the fetus's head "down" and the left side "pressed" against the mother's backbone and pelvis ( $\sim 5 \%$ of fetuses set in a left occiput anterior or transverse-LOA/LOT-uterine position and $\sim 12 \%$ with a ROA/ROT position). The LOA/LOT position constrains left arm movement and head turns directed toward the left side of the fetus, whereas the ROA/ROT position constrains right arm movements and rightward head turns.

The maintenance of fetal posture throughout much of the latter half of pregnancy likely affects the elasticity of the skin and muscles as well as calibrates some general "set points" in the muscle spindle cells in the muscles of the arm and neck and may produce lateral asymmetries in the organization of spinal synergies. According to Previc [52], the uterine position could produce a lateralized asymmetry in the development of the vestibular system. After delivery, gravity affects muscle stretches, which violate spindle set points; this, then, initiates contractions that produce the characteristic neonatal postures and hence accounts for their similarity to fetal postures [258]. In addition, the asymmetry of the vestibular sensitivity would produce a directional head-turn in order to create a balance of vestibular excitation. These factors could account for the neonatal population-level rightward head orientation preference [34,261]. Subsequent recalibrations of spindle set points and greater supraspinal influence eventuate in a postural change as a result of greater control relative to gravity and visual field, with head orientation preference moving toward the midline [262].

The neonate's supine head orientation preference (NSHOP) is predicted by the fetal position in utero as estimated during delivery [263]. Unfortunately, estimates of uterine position from delivery data are relatively weak, and, in this study (unlike [34]), only 52\% of the neonates showed significant NSHOPs. However, $80 \%$ of neonates with a leftward NSHOP were so predicted from the delivery estimate of their atypical (ROA/ROT) uterine birth position, and $75 \%$ of neonates with a rightward NSHOP were predicted by the delivery estimate of their typical (LOA/LOT) uterine position. HOP is likely a consequence of asymmetrically lateralized activation of neuromotor mechanisms that involve brain stem nuclei, cerebellum, thalamus, and basal ganglia [262,264]. These mechanisms developed in utero and likely were influenced by the fetus' position rather than simply a reflection of already existent hemispheric specialization [21,22].

As a consequence of their $\mathrm{HOP}$, a neonate is more responsive to auditory and tactile stimulation of one ear and cheek [261]. Turkewitz [261] was the first to propose that the neonatal lateralized asymmetry of sensory and motor characteristics is an early predictor of later forms of other lateralized functions, including handedness. In a study of more neonates, Michel [34] reported that the HOP of 150 ( 81 males) neonates was normally distributed but with a sharp rightward shift similar to the handedness distribution in adults [265]. About $10-12 \%$ of neonates showed a significant leftward HOP. From this group of neonates, 20 (11 males) were selected to have their hand-use preferences for prehension assessed at $12,16,22,32,40,51,60$, and 78 weeks postpartum. Ten (5 males) had a significant rightward NSHOP, and 10 had a significant leftward NSHOP.

The supine HOP of these 20 infants was assessed more extensively at 3, 6, and 8 weeks postpartum. The correlation between their brief neonatal and more elaborate post-neonatal HOP assessment values was significant, but 5 of the 20 infants seemed to have changed from their NSHOP assessment (three with initial leftward NSHOP became rightward SHOP and two with initial rightward NSHOP became leftward SHOP). However, both the NSHOP and the post-neonatal SHOP were significantly predictive of infant hand-use preferences for prehension throughout the eight assessments. However, the post-neonatal SHOP had the largest predictive relation [35]. What is remarkable about this study is that it was able to predict left-hand-use preference for reaching for objects from the infant's leftward SHOP. 
HOP results in the asymmetrically biased proprioceptive and visual experience of the hands and arms that contribute to the development of their visually guided control. Even relatively minor asymmetries in neuromotor action and visual experience of the left and right hands can produce differences in the cortical and subcortical mechanisms controlling motivated hand use $[266,267]$. The HOP also produces differences in limb actions, with the face-side hand/arm exhibiting more movement and grasping actions and being more available for visual regard [35,263].

Neonates move their right arms more frequently and take "swipes" at objects in their field of view. In addition, if objects are placed in the hands during the first 2 months postpartum, the right hand has a stronger grasp [268] and exhibits a longer duration of holding [269]. Since the direction of the neonate's HOP can produce such limb differences, these reported asymmetries are likely a consequence of the HOP [21]. That is, shifting the infant's head to the opposite of the preferred HOP results in a shift in the infant's hand and arm movements to the "new" face-side hand [34,244,245]. Hence, the HOP directly affects the early asymmetrical bias in hand and arm movements [264].

Ocklenburg et al. [123] examined 58 7- to 11-year-old children who suffered from congenital muscular torticollis (CMT), which tilts the infant's posture and head toward one side. Their handedness was assessed via acting out the EHI questions but left- and right-handedness was defined simply as less-than or greater-than 0 , respectively. All of the 31 children who had CMT with a left head-tilt were right-handed; whereas, only $78 \%$ of those with a right head-tilt were right-handed $(92 \%$ of the 54 control children were right-handed). The authors argue that the head-tilt rotates the face and eyes to the opposite side, resulting in the greater visual experience of the hand opposite the head-tilt (right hand for left head-tilt babies). However, this observation needs replication because even the authors' picture shows that the hand may not be in the visual field for the head-tilt. I have argued that it is the relative amount of time and movement of the hands in the visual field that likely affects the establishment of the visual-proprioceptive correspondence map that contributes to the success of one hand obtaining an object before the other (see below). Thus, investigating the handedness of children with CMT may not reveal the role of HOP in the development of infant handedness.

The HOP has disappeared by $8-10$ weeks, and the infant exhibits a midline position for the head [264]. However, the hand that was on the face-side during the earlier HOP is the same hand that is used initially for swiping at visually presented objects at 12-16 weeks [35]. By 4 months, infants exhibit "directed reaching" toward objects, and the hand used predominantly for this reaching is the face-side hand from the previous HOP. By 5-6 months, infants are able to acquire objects using the same hand that they used for directed reaching. Infants maintain this hand preference for acquiring objects for their next 12 months. Thus, the development of handedness during infancy begins with an HOP that creates asymmetrical motor actions and hand regard. These asymmetrical "experiences" predict the hand that will be later used for reaching.

The HOP likely creates an asymmetry in the visual-proprioceptive map of space. Since the face-side hand is moved more, it creates more proprioceptive and corollary neural activity, which can facilitate the association of that hand's position in visual space and its "felt" position relative to the body. Consequently, the face-side hand should have an advantage in reaching for objects located in space relative to the infant's body. That advantage concatenates into a greater probability of contacting the object and acquiring it. This would build more extensive cortical-basal ganglia reentrant circuits needed for the "motivational" control of that arm [266] and hence, a preference for its use.

There are large individual differences in the trajectories of handedness for object acquisition [142,151] during the period from 6 to 14 months postpartum. Nine monthly assessments permit the identification of the nonlinear individual and group developmental trajectories. However, fewer assessments fail to identify any developmental trend [142].

We assessed, monthly, the longitudinal development of hand-use preferences for 383 infants during the 6- to 14-month period [151] using a reliable and valid assessment 
procedure [137] capable of identifying significant differences $(p<0.05)$ in the use of each hand at each assessment. Four types of developmental trajectories for acquiring objects were observed $[143,270]$ : those who manifest an early stable right hand-use preference (about 32\%), those who manifest an early stable left hand-use preference (about 12\%), those (25\%) who manifest a later developing right-hand preference and those $(30 \%)$ who do not exhibit a stable hand preference during this age period. Thus, even during infancy, right hand-use preference predominates over left hand-use preference. Yet, 30\% of infants do not manifest a consistent preference for acquiring objects. The developmental consequences of this proportion of infants without a consistent hand preference require additional longitudinal research.

From 7 to 12 months postpartum, unimanual (e.g., banging or shaking the object) and nondifferentiated bimanual actions become more frequent [230]. A hand-use preference for unimanual actions appears by 11 months, and the direction of that preference is predicted by the previously established hand-use preference for acquiring objects [271,272]. Furthermore, the hand-use preference for acquiring objects predicts the hand-use preference in RDBM [273]. As a result of the hand-use preference for acquiring objects and manipulating them, the preferred hand will have established many more "programs" or "schemas" [221] that can be employed with any object that affords RDBM [230].

Infants exhibit RDBM as early as 7 months [230], but s only as a minor part of their repertoire, and it seems to emerge from the properties of the object rather than from the coordinated actions by the infant. However, by 13 months, infants begin to exhibit a hand-use preference for RDBM, and these RDBM actions appear to be coordinated rather than being simply afforded by the object [28]. Thus, both unimanual actions and RDBM actions are only a small portion of the infant's manual repertoire during the 6- to 14-month period, and hand-use preferences in those actions appear only in the later months.

By 11 months, infants manifest a hand preference for unimanual manipulation, which is predicted by their preference for acquiring objects [271]. Although a hand preference for the action of acquiring objects is relatively constant in the manual repertoire during the 6to 14-month age period, by 12-14 months, the strong hand-use preference for acquiring objects will appear to "weaken" as the infant more frequently uses the nonpreferred hand to acquire an object. Increasing the frequency of using the nonpreferred hand to acquire the object is most likely prompted by the desire to engage more immediately in RDBM actions with the preferred hand. However, this account requires further study.

By 18 months, infants are engaging primarily in RDBM with objects and can solve many tasks that require an RDBM action [274]. A toddler's hand-use preference for RDBM is predicted by their hand-use preference for acquisition as infants. Moreover, a group of infants who had no hand-use preference for acquiring objects developed a hand-use preference for RDBM as toddlers (65\% right-handed and 30\% left-handed). Annett ([109], p. 392) provided evidence from her peg-moving task that by $3-5$ years of age, the distribution of skill differences between the hands was equivalent to that of adults. That is, the same right-shift in the degree of handedness skill that is shown by adults is present in preschool children. Although some children may change their hand preference after 5 years of age, their subsequent pattern of handedness is likely to be different from those children who did not change the pattern established during their first 5 years Interestingly, the self-identity handedness fails to [275]. Thus, the right bias in hand-use preference can be observed quite early in infancy may continue through childhood.

Recently, Latta [276] was able to test the handedness (using an RDBM problem-solving task) of 58 five-year-old children of the 383 infants from whom we had collected data on infant hand-use preferences for acquiring objects at 6- to 14-months of age and toddler hand-use preferences for RDBM at 18- to 24-months of age. Hand preferences for both infant and toddler age groups were determined via latent class analysis.

Latta found that $35(60 \%)$ had right-hand preferences, and 11 (19\%) had left-hand preferences as infants (21\% had no preference). Of these infants, $74 \%$ (26) of those with a right preference retained a right preference as toddlers (two showed no preference), and 
$45 \%$ (5) retained a left preference as toddlers (four showed no preference). Comparing the infant hand preference to the hand preferences at 5 years of age, 74\% (26) of those infants with right preference retained a right preference at 5 years of age, and $55 \%$ (6) of those with a left preference retained their left preference. However, toddler RDBM hand-use preferences were a better predictor of five-year hand preference with 92\% (33) of those 36 with a toddler RDBM right preference retaining their right preference at five years and $78 \%$ (11) of those 14 with a left preference as toddlers retaining their left preference. If no preference consistencies are included in the analyses, $79 \%$ of the hand preference of 5 -year-old's is predicted from toddler RDBM preferences, whereas only $58 \%$ of the hand preference of 5-year-old's is predicted from infant hand preferences for acquiring objects.

Infant hand-use preference likely derives from prenatally and neonatally established postural asymmetries that facilitate a bias in visually guided hand use. Those same postural asymmetries exhibit a continuous distribution with a profound shift toward a right bias, but with a left minority, which would account for the early development of a left-hand-use preference. Differences in hand-use preference during infancy could be further separated into actions that resulted in contact with, and acquisition of, objects (CA), unimanual manipulation (UM) of objects, and role-differentiated bimanual manipulation (RDBM) of objects beginning in the latter half of the infant's first year. Each of these hand use preferences emerged in sequence during the infant's first year of sensorimotor development, and each only after the manual skill on which the hand preference was based had achieved a particular level of proficiency. Moreover, each preference served as a base upon which the subsequent preferences could build (Figure 2). Thus, unimanual manipulation preference reflected the earlier appearing acquisition preference, and the later appearing preference for RDBM reflected the earlier preferences of CA and UM. Of course, RDBM preferences serve as the basis for the establishment of a wide range of tool use, artifact construction, and manipulation skills manifested throughout childhood and adult handedness.

Since this sequence did not reflect the manifestation of a serial homology of infant handedness (derived from the same underlying mechanism that was maturing), the handedness in the sequence was neither absolute nor necessarily consistent. Rather, the relation across manifestation was probabilistic: right or left-handedness for contact/acquisition was stochastically associated with right or left-handedness in unimanual manipulation or RDBM, and so on. The trajectory of development assured a right-hand predominance in the population with a left-hand minority, but, essentially, handedness is a continuously distributed trait (not categorical) with a right shift for each manifestation. Nevertheless, there is a very suitable predictive relation across the manifestations for both a right and especially left preference. This cascading effect of the postural origin of handedness provides a developmental explanation for the right bias in the population, the maintenance of a minority of left-handedness, and the continuum of handedness across individuals.

\section{Significance of Handedness for Hemispheric Specialization and Coordination}

The reason researchers investigate the relation of handedness to people's cognitive, social, and emotional functioning is because handedness is thought to represent different patterns of hemispheric specialization. It is this pattern of hemispheric specialization (not handedness, per se) that is believed to affect psychological functions. Studies of children and adults [277,278] suggest that left- and right-handed infants may be developing symbolic and abstract concepts differently. Since left-handedness is not the mirror image of right-handedness [70] but rather represents its own pattern of neurobehavioral organization $[279,280]$ and development [270], the apparent differences in children and adult psychological functions that are associated with their handedness would not be mirror images either. What, then, does that mean for the large proportion of infants ( 30\%, [270]) who exhibit no hand-use preference? Does developing handedness status early or late affect the development of language abilities, object construction skills, tool-using skills, visual-spatial abilities, executive functioning, etc.? We propose that the four patterns of de- 
veloping handedness that we discovered are associated with differences in the development of these abilities.

Kotwica, Ferre, and Michel [281] reported that infants without a consistent hand-use preference were delayed in developing the kind of object management skills considered to be important in the development of symbolic abilities [282]. Similarly, Marcinowski and colleagues observed that hand-use preferences during infancy predicted advances in the development of the skill for stacking blocks [143]. Infants with early left- or right-hand-use preferences exhibited stacking skills earlier than infants both without a preference and those who only later developed a right-hand-use preference. Moreover, advanced skills for stacking blocks during infancy predicted advances in the comprehension of spatial words at three years of age without any general advances in language skills or cognitive ability [283].

Nelson and colleagues discovered that toddler hand preferences for RDBM predicted language skills at 2, 3, and 5 years of age. Indeed, infants who showed consistent early right-hand-use from 6 to 14 months of age had advanced language skills (Bayley Scales III) at two years of age; whereas, those children who were inconsistent in their handedness as infants but later developed handedness as toddlers were not advanced for language development [274]. In addition, toddlers who had the strongest and most consistent righthand-use preference from 18 to 24 months had higher expressive and receptive language scores at three years of age (measured with Preschool Language Scales, 5th edition) than toddlers with a left-hand-use preference or with a weak right-hand-use preference [284]. By five years of age, children, who as toddlers, had a strong right-hand-use preference, scored significantly higher on both expressive and receptive language skills (PLS-5) compared to those with a left-hand-use preference or a weak right-hand-use preference [285]. Thus, individual differences in fine motor skills (RDBM) during toddlerhood can have cascading effects on language ability during the preschool years.

If handedness is relevant for advancing the development of tool-using skills [286] and symbolic abilities, then infant handedness likely plays a role in infant cognitive, social, and emotional development. Some developmental scientists have argued that during human development, various cognitive, social, and emotional abilities are built upon, scaffolded by, or bootstrapped from, early sensorimotor skills (e.g., [287]). Indeed, embodied cognition theory proposes that every psychological construct (e.g., executive function, symbol use, thinking, emotional communication, etc.) derives from sensorimotor development and the experiences provided by that development (e.g., [288,289]).

As future research charts the trajectories of handedness development into the schoolaged period, we may discover how preschool measures of design-copying skills manage to become such suitable predictors of middle school mathematics, science, and reading achievement test scores $[290,291]$. Although skills for copying designs are conventionally interpreted as visual-spatial abilities, I would argue that they may more appropriately represent visual-motor manual skills (cf., [292,293]). As such, individuals with early handuse preferences ought to exhibit better skills in copying designs than those without early hand-use preferences. I would propose that if early handedness development is related to better design-copying skills of children, then the four patterns of infant handedness development that we discovered may represent the four patterns of neurobehavioral development highly relevant for understanding the development of scientific, reading, and math skills.

Since neural organization and processing can be extended and/or modified during development [221,294] to produce neural systems for subsequent psychological functioning that may not resemble their earlier developmental character, studies of adult HS/HC are unlikely to reveal much about the character of their developmental origin. For example, there appear to be fundamental differences between the way in which the developing brain and the adult brain process and produce speech and language (cf., [295]). Consequently, investigation of the development of handedness, hemispheric specialization, and inter- 
hemispheric communication and coordination should be a priority both in neuroscience and clinical neurology [138].

Elsewhere, I have sketched out a program for how to examine the relation of the development of handedness to the development of other cognitive abilities [46]. Moreover, we [25] described how modern developmental biological processes of heterochrony, heterotopy, heterometry, and heterotypy could apply to the study of human psychological development. Application of these processes to the development of those psychological functions that are the current focus of investigations of HS/HC would avoid the use of misleading concepts that cause scientists to seek evidence of nature-nurture interactions in development, biological essentialism in the formation of functional categories, and the adoption of a "development to" approach in their investigations.

\section{Concluding Remarks}

Using performance-based measures, the early development of handedness is a cascade of lateral symmetries derived from the neonatal postural asymmetry, which, in turn, is likely derived from uterine position asymmetry. This developmental approach accounts for the extensive right shift in handedness distribution, the maintenance of a left-handed minority, and the continuous (rather than categorical) character of handedness. This developmental approach can be applied to investigating the development of other functions of hemispheric specialization and to interhemispheric coordination and communication. With more detailed accounts of the development of other lateralized functions, research can begin to address issues of heterochrony, heterotypy, heterometry, and heterotopy among the different developmental trajectories $[25,99]$. Such knowledge will help identify those factors responsible for both the maintenance and the alterations of trajectories. That will create more powerful explanations of $\mathrm{HS} / \mathrm{HC}$; therefore, I believe that it is time to challenge conventional wisdom.

Funding: This is a review paper that did not receive external funding.

Institutional Review Board Statement: This is a review of many studies, all of which had published accounts of the IRB approval.

Informed Consent Statement: Again, this is a review of many studies all of which published how the informed consent was acquired.

Data Availability Statement: No non-published data were presented in this review.

Acknowledgments: The author would like to thank two anonymous reviewers whose suggestions greatly improved this manuscript. Of course, the author is solely responsible for the content of this manuscript, but I would like to thank the many undergraduate and graduate students, parents, and especially their infants who have participated in the various studies conducted by the author and colleagues.

Conflicts of Interest: The author has no conflicts of interest.

\section{References}

1. Prieur, J.; Lemasson, A.; Barbu, S.; Blois-Heulin, C. History, development and current advances concerning the evolutionary roots of human right-handedness and language: Brain lateralisation and manual laterality in non-human primates. Ethology 2019, 125, 1-28. [CrossRef]

2. De Haan, E.H.F.; Corballis, P.M.; Hillyard, S.A.; Marzi, C.A.; Seth, A.; Lamme, V.A.F.; Volz, L.; Fabri, M.; Schechter, E.; Bayne, T.; et al. Split-Brain: What We Know Now and Why This is Important for Understanding Consciousness. Neuropsychol. Rev. 2020, 30, 224-233. [CrossRef]

3. Vingerhoets, G. Phenotypes in hemispheric functional segregation? Perspectives and challenges. Phys. Life Rev. 2019, 30, 1-18. [CrossRef] [PubMed]

4. Jasper, J.D.; Christman, S.D.; Clarkson, E. Predicting interactions in handedness research: The role of integrated versus independent dual-processes. Laterality Asymmetries Body Brain Cogn. 2021, 15, 1-17. [CrossRef]

5. Güntürkün, O.; Ocklenburg, S. Ontogenesis of Lateralization. Neuron 2017, 94, 249-263. [CrossRef]

6. Beer, C.G. Species-typical behavior and Ethology. In ComParative Psychology: A Modern Survey; Dewsbury, D.A., Rethlingshafer, D.A., Eds.; McGraw-Hilll: New York, NY, USA, 1973; pp. 21-77. 
7. Lehrman, D.S. Critique of Konrad Lorenz's Theory of Instinctive Behaviour. Q. Rev. Biol. 1953, 28, 337-363. [CrossRef]

8. Lehrman, D.S. Semantic and conceptual issues in the nature-nurture problem. In Development and Evolution of Behavior; Aronson, L.E., To-bach, E., Lehrman, D.S., Rosenblatt, J.S., Eds.; Freeman: San Francisco, CA, USA, 1970; pp. 17-52.

9. Michel, G.F. The roles of environment, experience, and learning in behavioral development. In Handbook of Developmental Science, Behavior and Genetics; Hood, K., Halpern, C., Greenberg, G., Lerner, R., Eds.; Wiley: Malden, MA, USA, 2010 ; pp. 123-165.

10. Michel, G.F.; Moore, C.L. Developmental Psychobiology: An Interdisciplinary Science; The MIT Press: Cambridge, MA, USA, 1995.

11. Lehrman, D.S. Interaction between internal and external environments in the regulation of the reproduc-tive cycle of the Ring Dove. In Sex and Behavior; Beach, F.A., Ed.; Wiley: New York, NY, USA, 1965; pp. 355-380.

12. Michel, G.F. Experiential influences in hormonally dependent ring dove parental care. In Reproduction: A Behavioral and Neuroendocrine Perspective; Komisaruk, B.R., Siegel, H.I., Chen, M.-F., Feder, H.H., Eds.; Annals of the New York Academy of Science: New York, NY, USA, 1986; pp. 158-169.

13. Michel, G.F. Doing what comes naturally: The role of self-generated experience in behavioral development. Eur. J. Dev. Sci. 2007, 1, 155-164. [CrossRef]

14. Michel, G.F.; Tyler, A.N. Developing human nature: “Development to" vs. Development from". Dev. Psychobiol. 2007, 49, 788-799. [CrossRef]

15. Corballis, M.C. Language Evolution: A Changing Perspective. Trends Cogn. Sci. 2017, 21, 229-236. [CrossRef] [PubMed]

16. Corballis, M.C.; Badzakova-Trajkov, G.; Häberling, I.S. Right hand, left brain: Genetic and evolutionary bases of cerebral asymmetries for language and manual action. Wiley Interdiscip. Rev. Cogn. Sci. 2011, 3, 1-17. [CrossRef]

17. Badzakova-Trajkov, G.; Corballis, M.; Häberling, I. Complementarity or independence of hemispheric specializations? A brief review. Neuropsychologia 2016, 93, 386-393. [CrossRef]

18. Mazoyer, B.; Zago, L.; Jobard, G.; Crivello, F.; Joliot, M.; Perchey, G.; Mellet, E.; Petit, L.; Tzourio-Mazoyer, N. Gaussian Mixture Modeling of Hemispheric Lateralization for Language in a Large Sample of Healthy Individuals Balanced for Handedness. PLoS ONE 2014, 9, e101165. [CrossRef]

19. Michel, G.F.; Babik, I.; Nelson, E.L.; Campbell, J.M.; Marcinowski, E.C. How the development of handedness could contribute to the development of language. Dev. Psychobiol. 2013, 55, 608-620. [CrossRef]

20. Packheiser, J.; Schmitz, J.; Arning, L.; Beste, C.; Güntürkün, O.; Ocklenburg, S. A large-scale estimate on the relationship between language and motor lateralization. Sci. Rep. 2020, 10, 1-10. [CrossRef]

21. Michel, G.F. Development of hand-use preference during infancy. In Manual Specialization and the Developing Brain; Young, G., Segalowitz, S., Corter, C., Trehub, S., Eds.; Academic Press: New York, NY, USA, 1983; pp. 33-70.

22. Michel, G.F. A neuropsychological perspective on infant sensorimotor development. In Advances in Infancy Research; Lipsitt, L.P., Rovee-Collier, C.K., Eds.; Ablex Pub. Corp.: Norwood, NJ, USA, 1988; Volume 5, pp. 1-37.

23. Michel, G.F. A Developmental-Psychobiological Approach to Developmental Neuropsychology. Dev. Neuropsychol. 2001, 19, 11-32. [CrossRef]

24. Michel, G.F. Development of infant handedness. In Conceptions of Development: Lessons from the Laboratory; Lewkowicz, D., Lickliter, R., Eds.; Psychology Press: Philadelphia, PA, USA, 2002; pp. 165-186.

25. Michel, G.F.; Babik, I.; Nelson, E.L.; Campbell, J.M.; Marcinowski, E.C. Evolution and development of handedness: An Evo-Devo approach. In Cerebral Lateralization and Cognition: Evolutionary and Developmental Investigations of Motor Biases; Forrester, G., Hudry, K., Lindell, A., Hopkins, W.D., Eds.; Elsevier: Amsterdam, The Netherlands, 2018; pp. 347-374. [CrossRef]

26. Michel, G.F.; Marcinowski, E.C.; Babik, I.; Campbell, J.M.; Nelson, E.L. An Interdisciplinary Biopsycho-social Perspective on Psychological Development. In Handbook of Infant Development: Biopsychosocial Perspectives; Calkins, S.D., Ed.; Guilford Publications: New York, NY, USA, 2015; pp. 427-446.

27. Michel, G.F. A Developmental Psychobiological Approach to Human Development. Res. Hum. Dev. 2014, 11, 37-49. [CrossRef]

28. Kimmerle, M.; Ferre, C.L.; Kotwica, K.A.; Michel, G.F. Development of role-differentiated bimanual manipulation during the infant's first year. Dev. Psychobiol. 2010, 52, 168-180. [CrossRef] [PubMed]

29. Annett, M. Handedness and Brain Asymmetry: The Right Shift Theory; Psychology Press: Hove, UK, 2002.

30. Young, G. Causality and Neo-Piagetian/ Neo-Eriksonian Neo-Stages. In Development: Toward Unifying Psychology; Springer: Berlin/Heidelberg, Germany, 2019.

31. McManus, C. Right Hand, Left Hand: The Origins of Asymmetry in Brains, Bodies, Atoms, and Cultures; Harvard University Press: Cambridge, MA, USA, 2002.

32. Lorenz, K. Evolution and Modification of Behaviour; University of Chicago Press: Chicago, IL, USA, 1965.

33. Popper, K.R. The Logic of Scientific Discovery; Torch Books: Harper, KS, USA, 1959.

34. Michel, G. Right-handedness: A consequence of infant supine head-orientation preference? Science 1981, 212, 685-687. [CrossRef] [PubMed]

35. Michel, G.F.; Harkins, D.A. Postural and lateral asymmetries in the ontogeny of handedness during infancy. Dev. Psychobiol. 1986, 19, 247-258. [CrossRef] [PubMed]

36. Strevens, M. The Knowledge Machine: How Irrationality Created Modern Science; W. W. Norton: New York, NY, USA, 2020.

37. Kuhn, T.S. The Structure of Scientific Revolutions; University of Chicago Press: Chicago, IL, USA, $1962 ;$ p. 172.

38. Kuhn, T.S. The structure of scientific revolutions; 50th Anniversary edition; University of Chicago Press: Chicago, IL, USA, 2012. 
39. Johnstone, L.T.; Karlsson, E.M.; Carey, D.P. The validity and reliability of quantifying hemispheric specialisation using fMRI: Evidence from left and right handers on three different cerebral asymmetries. Neuropsychologia 2020, 138, 107331. [CrossRef]

40. Vul, E.; Harris, C.R.; Winkielman, P.; Pashler, H. Puzzlingly High Correlations in fMRI Studies of Emotion, Personality, and Social Cognition. Perspect. Psychol. Sci. 2009, 4, 274-290. [CrossRef]

41. Bradshaw, A.R.; Bishop, D.V.; Woodhead, Z.V. Methodological considerations in assessment of language lateralisation with fMRI: A systematic review. Peer] 2017, 5, e3557. [CrossRef]

42. Paszulewicz, J.; Wolski, P.; Gajdek, M. Is laterality adaptive? Pitfalls in disentangling the laterality-performance relationship. Cortex 2020, 125, 175-189. [CrossRef]

43. Flevaris, A.V.; Robertson, L.C. Spatial frequency selection and integration of global and local infor-mation in visual processing: A selective review and tribute to Shlomo Bentin. Neuropsychologia 2016, 83, 192-200. [CrossRef] [PubMed]

44. Guenther, F.H.; Hickok, G. Neural models of motor speech control. In Neurobiology of Language; Hickok, G., Small, S.L., Eds.; Academic Press: Amsterdam, The Netherlands, 2016; pp. 725-740.

45. Vuoksimaa, E.; Koskenvuo, M.; Rose, R.J.; Kaprio, J. Origins of handedness: A nationwide study of 30161 adults. Neuropsychologia 2009, 47, 1294-1301. [CrossRef]

46. Michel, G.F. How Might the Relation of the Development of Hand Preferences to the Development of Cognitive Functions be Examined During Infancy: A Sketch? Front. Neurosci. 2018, 11, 739. [CrossRef]

47. Albouy, P.; Benjamin, L.; Morillon, B.; Zatorre, R.J. Distinct sensitivity to spectrotemporal modulation supports brain asymmetry for speech and melody. Science 2020, 367, 1043-1047. [CrossRef]

48. Deco, G.; Tononi, G.; Boly, M.; Kringelbach, M.L. Rethinking segregation and integration: Contributions of whole-brain modelling. Nat. Rev. Neurosci. 2015, 16, 430-439. [CrossRef]

49. Sergent, J. Theoretical and methodological consequences of variations in exposure duration in visual laterality studies. Percept. Psychophys. 1982, 31, 451-461. [CrossRef]

50. Sergent, J. Influence of task and input factors on hemispheric involvement in face processing. J. Exp. Psychol. Hum. Percept. Perform. 1985, 11, 846-861. [CrossRef]

51. Godfrey, H.K.; Grimshaw, G.M. Emotional language is all right: Emotional prosody reduces hemispheric asymmetry for linguistic processing. Laterality Asymmetries Body Brain Cogn. 2015, 21, 1-17. [CrossRef] [PubMed]

52. Previc, F.H. A general theory concerning the prenatal origins of cerebral lateralization in humans. Psychol. Rev. 1991, 98, 299-334. [CrossRef]

53. Deutsch, D. Dichotic Listening to Melodic Patterns and Its Relationship to Hemispheric Specialization of Function. Music. Percept. Interdiscip. J. 1985, 3, 127-154. [CrossRef]

54. Efron, R.; Koss, B.; Yund, E. Central auditory processing *1IV. Ear dominance?Spatial and temporal complexity. Brain Lang. 1983, 19, 264-282. [CrossRef]

55. Thatcher, R.W. Neurolinguistics: Theoretical and evolutionary perspectives. Brain Lang. 1980, 11, 235-260. [CrossRef]

56. Wang, Y.; Jongman, A.; Sereno, J. Dichotic perception of Mandarin tones by Chinese and American listeners. Brain Lang. 2001, 78 , 332-348. [CrossRef]

57. Wang, Y.; Behne, D.M.; Jongman, A.; Sereno, J.A. The role of linguistic experience in the hemispheric processing of lexical tone. Appl. Psycholinguist. 2004, 25, 449-466. [CrossRef]

58. Moen, I. Functional Lateralization of the Perception of Norwegian Word Tones-Evidence from a Dichotic Listening Experiment. Brain Lang. 1993, 44, 400-413. [CrossRef]

59. Best, C.T.; Avery, R.A. Left-Hemisphere Advantage for Click Consonants is Determined by Linguistic Significance and Experience. Psychol. Sci. 1999, 10, 65-70. [CrossRef]

60. Shtyrov, Y.; Pihko, E.; Pulvermüller, F. Determinants of dominance: Is language laterality explained by physical or linguistic features of speech? NeuroImage 2005, 27, 37-47. [CrossRef]

61. Levine, S.C.; Banich, M.T.; Koch-Weser, M.P. Face recognition: A general or specific language on judgments of facial expressions of right hemisphere capacity? Brain Cogn. 1988, 8, 303-325. [CrossRef]

62. Patterson, K.; Bradshaw, J. Differential hemispheric mediation of non-verbal visual stimuli. J. Exp. Psychol. 1975, 1, $246-252$.

63. Leleu, A.; Rekow, D.; Poncet, F.; Schaal, B.; Durand, K.; Rossion, B.; Baudouin, J. Maternal odor shapes rapid face categorization in the infant brain. Dev. Sci. 2019, 23, e12877. [CrossRef]

64. Forrester, G.S.; Todd, B.K. A comparative perspective on lateral biases and social behavior. In Cerebral Lateralization and Cognition: Evolutionary and Developmental Investigations of Motor Biases; Forrester, G., Hudry, K., Lindell, A., Hopkins, W.D., Eds.; Elsevier: Amsterdam, The Netherlands, 2018; pp. 377-403. [CrossRef]

65. Pflug, A.; Gompf, F.; Muthuraman, M.; Groppa, S.; Kell, C.A. Differential contributions of the two human cerebral hemispheres to action timing. eLife 2019, 8, 48404. [CrossRef]

66. Sainburg, R.L. Evidence for a dynamic-dominance hypothesis of handedness. Exp. Brain Res. 2002, 142, 241-258. [CrossRef] [PubMed]

67. Sainburg, R.L. Handedness: Differential Specializations for Control of Trajectory and Position. Exerc. Sport Sci. Rev. 2005, 33, 206-213. [CrossRef] [PubMed]

68. Przybyla, A.; Good, D.C.; Sainburg, R.L. Dynamic dominance varies with handedness: Reduced inter-limb asymmetries in left-handers. Exp. Brain Res. 2012, 216, 419-431. [CrossRef] [PubMed] 
69. Laland, K.N. Exploring gene-culture interactions: Insights from handedness, sexual selection and niche-construction case studies. Philos. Transac. R. Soc. B 2008, 363, 3577-3589. [CrossRef]

70. Michel, G.F. A lateral bias in the neuropsychological functioning of human infants. Dev. Neuropsychol. 1998, 14, 445-469. [CrossRef]

71. Sainburg, R.L. Convergent models of handedness and brain lateralization. Front. Psychol. 2014, 5, 1092. [CrossRef]

72. Andersen, K.W.; Siebner, H.R. Mapping dexterity and handedness: Recent insights and future chal-lenges. Curr. Opin. Behav. Sci. 2018, 20, 123-129. [CrossRef]

73. Goble, D.J.; Brown, S.H. The biological and behavioral basis of upper limb asymmetries in sensorimo-tor performance. Neurosci. Biobehav. Rev. 2008, 32, 598-610. [CrossRef] [PubMed]

74. Woytowicz, E.J.; Westlake, K.P.; Whitall, J.; Sainburg, R.L. Handedness results from complementary hemispheric dominance, not global hemispheric dominance: Evidence from mechanically coupled bilateral movements. J. Neurophysiol. 2018, 120, 729-740. [CrossRef] [PubMed]

75. Nicolini, C.; Harasym, D.; Turco, C.V.; Nelson, A.J. Human motor cortical organization is influenced by handedness. Cortex 2019, 115, 172-183. [CrossRef]

76. Marcori, A.J.; Monteiro, P.H.M.; Okazaki, V.H.A. Changing handedness: What can we learn from preference shift studies? Neurosci. Biobehav. Rev. 2019, 107, 313-319. [CrossRef]

77. Hammond, G. Correlates of human handedness in primary motor cortex: A review and hypothesis. Neurosci. Biobehav. Rev. 2002, 26, 285-292. [CrossRef]

78. Schmitz, J.; Metz, G.A.; Güntürkün, O.; Ocklenburg, S. Beyond the genome-Towards an epigenetic understanding of handedness ontogenesis. Prog. Neurobiol. 2017, 159, 69-89. [CrossRef]

79. Wiper, M.L. Evolutionary and mechanistic drivers of laterality: A review and new synthesis. Laterality 2017, 22, 740-770. [CrossRef] [PubMed]

80. Sha, Z.; Schijven, D.; Carrion-Castillo, A.; Joliot, M.; Mazoyer, B.; Fisher, S.E.; Crivello, F.; Francks, C. The genetic architecture of structural left-right asymmetry of the human brain. Nat. Hum. Behav. 2021, 1-14. [CrossRef]

81. Gonzalez, C.L.R.; van Rootslaar, N.A.; Gibb, R.L. Sensorimotor lateralization scaffolds cognitive specialization. In Cerebral Lateralization and Cognition: Evolutionary and Developmental Investigations of Motor Biases; Forrester, G., Hudry, K., Lindell, A., Hopkins, W.D., Eds.; Elsevier: Amsterdam, The Netherlands, 2018; pp. 405-433. [CrossRef]

82. Brandler, W.M.; Morris, A.P.; Evans, D.M.; Scerri, T.S.; Kemp, J.P.; Timpson, N.J.; Pourcain, B.S.; Smith, G.D.; Ring, S.M.; Stein, J.; et al. Common Variants in Left/Right Asymmetry Genes and Pathways Are Associated with Relative Hand Skill. PLoS Genet. 2013, 9, e1003751. [CrossRef]

83. Rogers, L.J. Evolution of Hemispheric Specialization: Advantages and Disadvantages. Brain Lang. 2000, 73, 236-253. [CrossRef]

84. Rogers, L.J.; Vallortigara, G.; Andrew, R.J. Divided Brains: The Biology and Behaviour of Brain Asymmetries; Cambridge University Press: Cambridge, UK, 2013.

85. Fragaszy, D.M.; Mitchell, S.R. 1990 Hand preference and performance on unimanual and bimanual tasks in capuchin monkeys (Cebus apella). J. Comp. Psychol. 1990, 104, 275-282. [CrossRef]

86. Dadda, M.; Agrillo, C.; Bisazza, A.; Brown, C. Laterality enhances numerical skills in the guppy, Poecilia reticulata. Front. Behav. Neurosci. 2015, 9, 285. [CrossRef] [PubMed]

87. Baraud, I.; Buytet, B.; Bec, P.; Blois-Heulin, C. Social laterality and 'transversality' in two species of mangabeys: Influence of rank and implication for hemispheric specialization. Behav. Brain Res. 2009, 198, 449-458. [CrossRef]

88. Chapelain, A.; Pimbert, P.; Aube, L.; Perrocheau, O.; Debunne, G.; Bellido, A.; Blois-Heulin, C. Can Population-Level Laterality Stem from Social Pressures? Evidence from Cheek Kissing in Humans. PLoS ONE 2015, 10, e0124477. [CrossRef]

89. Vallortigara, G.; Rogers, L.J. Survival with an asymmetrical brain: Advantages and disadvantages of cerebral lateralization. Behav. Brain Sci. 2005, 28, 575-589. [CrossRef]

90. Michel, G.F.; Harkins, D.S. Concordance of handedness between teacher and student facilitates learning manual skills. J. Hum. Evol. 1985, 14, 597-601. [CrossRef]

91. Uomini, N.; Lawson, R. Effects of Handedness and Viewpoint on the Imitation of Origami-Making. Symmetry 2017, 9, 182. [CrossRef]

92. Mebert, C.J.; Michel, G.F. Handedness in Artists. In Neuropsychology of Left-Handedness; Elsevier: Amsterdam, The Netherlands, 1980; pp. 273-279.

93. Michel, G.F.; Nelson, E.L.; Babik, I.; Campbell, J.M.; Marcinowski, E.C. Multiple Trajectories in the Developmental Psychobiology of Human Handedness. In Embodiment and Epigenesis: Theoretical and Methodological Issues in Understanding the Role of Biology within the Relational Developmental System Part B: Ontogenetic Dimensions; Lerner, R.M., Benson, J.B., Eds.; Elsevier: Amsterdam, The Netherlands, 2013; pp. 227-260.

94. Bishop, D.V.M. Cerebral Asymmetry and Language Development: Cause, Correlate, or Consequence? Science 2013, $340,1230531$. [CrossRef] [PubMed]

95. Prieur, J.; Lemasson, A.; Barbu, S.; Blois-Heulin, C. Challenges Facing the Study of the Evolutionary Origins of Human RightHandedness and Language. Int. J. Primatol. 2018, 39, 183-207. [CrossRef]

96. MacNeilage, P.F. Present Status of the Postural Origins Theory. Spec. Top. Primatol. 2007, 5, 58-91. [CrossRef] 
97. MacNeilage, P.F.; Studdert-Kennedy, M.G.; Lindblom, B. Primate handedness reconsidered. Behav. Brain Sci. 1987, 10, 247-263. [CrossRef]

98. Papademetriou, E.; Sheu, C.-F.; Michel, G.F. A meta-analysis of primate hand preference for reaching and other hand-use preferences. J. Comp. Psychol. 2005, 119, 33-48. [CrossRef]

99. Michel, G.F. The concept of homology in the development of handedness. Dev. Psychobiol. 2012, 55, 84-91. [CrossRef] [PubMed]

100. Volkmann, J.; Schnitzler, A.; Witte, O.W.; Freund, H.-J. Handedness and asymmetry of hand representation in human motor cortex. J. Neurophysiol. 1997, 79, 2149-2154. [CrossRef]

101. Bavelier, D.; Bediou, B.; Green, C.S. Expertise and generalization: Lessons from action video games. Curr. Opin. Behav. Sci. 2018, 20, 169-173. [CrossRef]

102. Atz, J.W. The application of the idea of homology to behavior. In Development and Evolution of Behavior; Aronson, L.R., Tobach, E., Lehrman, D.S., Rosenblatt, J.S., Eds.; Freeman: New York, NY, USA, 1970; pp. 53-74.

103. Pribram, K. Comparative neurology and the evolution of behavior. In Behavior and Evolution; Roe, A., Simpson, G.G., Eds.; Yale University Press: New Haven, CT, USA, 1958; pp. 140-164.

104. Kutch, J.J.; Valero-Cuevas, F.J. Challenges and New Approaches to Proving the Existence of Muscle Synergies of Neural Origin. PLoS Comput. Biol. 2012, 8, e1002434. [CrossRef]

105. Oppenheim, R.W. Ontogenetic adaptations in neural and behavioural development: Toward a more "ecological" developmental psychobiology. In Continuity of Neural Functions from Prenatal to Postnatal Life; Prechtl, H.F.R., Ed.; Lippincott: Philadelphia, PA, USA, 1984; pp. 16-29.

106. Camras, L.A.; Sullivan, J.; Michel, G. Do infants express discrete emotions? Adult judgments of facial, vocal, and body actions. J. Nonverbal. Behav. 1993, 17, 171-186. [CrossRef]

107. Michel, G.F.; Camras, L.A.; Sullivan, J. Infant interest expressions as coordinative motor structures. Infant Behav. Dev. 1992, 15, 347-358. [CrossRef]

108. Camras, L.A.; Witherington, D.C. Dynamical systems approaches to emotional development. Dev. Rev. 2005, 25, 328-350. [CrossRef]

109. Annett, M. Left, Right, Hand and Brain: The Right Shift Theory; Lawrence Erlbaum Associates Ltd.: Hove, UK, 1985.

110. McManus, I.C.; Bryden, M.P. The genetics of handedness, cerebral dominance and lateralization. In Handbook of Neuropsychology. Child Neuropsychology; Rapinand, I., Segalowitz, S., Eds.; Elsevier: Amsterdam, The Netherlands, 1992; Volume 6, pp. 115-142.

111. Medland, S.E.; Duffy, D.L.; Wright, M.J.; Geffen, G.M.; Martin, N.G. Handedness in twins: Joint analysis of data from 35 samples. Off. J. Int. Soc. Twin Stud. 2006, 9, 46-53. [CrossRef]

112. Risch, N.; Pringle, G. Segregation analysis of human hand preference. Behav. Genet. 1985, 15, 385-400. [CrossRef] [PubMed]

113. Warren, D.M.; Stern, M.; Duggirala, R.; Dyer, T.D.; Almasy, L. Heritability and linkage analysis of hand, foot, and eye preference in Mexican Americans. Laterality 2006, 11, 508-524. [CrossRef] [PubMed]

114. Granville, D.; Ehrman, L.; Perelle, I.B. Laterality Survey. Mensa Bull. 1979, 224, 15-16.

115. Perelle, I.B.; Ehrman, L. An international study of human handedness: The data. Behav. Genet. 1994, 24, 217-227. [CrossRef]

116. Annett, M. Hand Preference and the Laterality of Cerebral Speech. Cortex 1975, 11, 305-328. [CrossRef]

117. Harkins, D.A.; Michel, G.F. Evidence for a maternal influence on infant hand-use preferences. Dev. Psychobiol. 1988, $21,535-542$. [CrossRef]

118. McKeever, W.F. A new family handedness sample with findings consistent with X-linked transmission. Br. J. Psychol. 2000, 91, 21-39. [CrossRef] [PubMed]

119. McManus, I.C. The Inheritance of Left-Handedness. Novartis Found. Symp. 2007, 162, 251-281. [CrossRef]

120. Michel, G.F. Maternal influences on infant hand-use during play with toys. Behav. Genet. 1992, 22, 163-176. [CrossRef]

121. McManus, I.C.; Davison, A.; Armour, J.A.L. Multilocus genetic models of handedness closely resemble single-locus models in explaining family data and are compatible with genome-wide association studies. Ann. N. Y. Acad. Sci. 2013, 1288, 48-58. [CrossRef]

122. Cuellar-Partida, G.; Tung, J.Y.; Eriksson, N.; Albrecht, E.; Aliev, F.; Andreassen, O.A.; Barroso, I.; Beckmann, J.S.; Boks, M.P.; Boomsma, D.I.; et al. Genome-wide association study identifies 48 common genetic variants associated with handedness. Nat. Hum. Behav. 2021, 5, 59-70. [CrossRef] [PubMed]

123. Ocklenburg, S.; Bürger, C.; Westermann, C.; Schneider, D.; Biedermann, H.; Güntürkün, O. Visual experience affects handedness. Behav. Brain Res. 2010, 207, 447-451. [CrossRef] [PubMed]

124. Odintsova, V.; Sudermann, M.; Hagenbeek, F.; Caramaschi, D.; Hottenga, J.J.; Pool, R.; Dolan, C.; Ligthart, L.; van Beijsterveldt, C.; Willemsen, G. Epigenome-wide association study of left-handedness for different tissues and ages. Res. Square 2021, preprint. [CrossRef]

125. McManus, I.C.; Van Horn, J.D.; Bryden, P.J. The Tapley and Bryden test of performance differences between the hands: The original data, newer data, and the relation to pegboard and other tasks. Laterality Asymmetries Body Brain Cogn. 2016, 21, 371-396. [CrossRef]

126. Cavanagh, T.; Berbesque, J.C.; Wood, B.; Marlowe, F. Hadza handedness: Lateralized behaviors in a contemporary hunter-gatherer population. Evol. Hum. Behav. 2016, 37, 202-209. [CrossRef]

127. Perelle, I.B.; Ehrman, L. On the other hand. Behav. Genet. 2005, 35, 343-350. [CrossRef] [PubMed]

128. Oldfield, R.C. The assessment and analysis of handedness: The Edinburgh inventory. Neuropsychologia 1971, 9, 97-113. [CrossRef] 
129. Bryden, M. Measuring handedness with questionnaires. Neuropsychologia 1977, 15, 617-624. [CrossRef]

130. Annett, M. A classification of hand preference by association analysis. Br. J. Psychol. 1970, 61, 303-321. [CrossRef]

131. Nelson, E.L.; Gonzalez, S.L.; El-Asmar, J.M.; Ziade, M.F.; Abu-Rustum, R.S. The home handedness questionnaire: Pilot data from preschoolers. Laterality Asymmetries Body Brain Cogn. 2018, 24, 482-503. [CrossRef] [PubMed]

132. Dragovic, M.; Milenković, S.; Hammond, G. The distribution of hand preference is discrete: A taxometric examination. Br. J. Psychol. 2008, 99, 445-459. [CrossRef]

133. Healey, J.M.; Liederman, J.; Geschwind, N. Handedness is not a unidimnsional trait. Cortex 1986, 22, 33-53. [CrossRef]

134. Steenhuis, R.E.; Bryden, M.P. Different dimensions of hand preference that relate to skilled and un-skilled activities. Cortex 1989, 25, 289-304. [CrossRef]

135. Michel, G.F.; Sheu, C.-F.; Brumley, M.R. Evidence of a right-shift factor affecting hand-use preferences from seven- to elevenmonths of age as revealed by latent class analysis. Dev. Psychobiol. 2002, 40, 1-12. [CrossRef]

136. Baciu, M.; Juphard, A.; Cousin, E.; Le Bas, J.F. Evaluating fMRI methods for assessing hemispheric language dominance in healthy subjects. Eur. J. Radiol. 2005, 55, 209-218. [CrossRef]

137. Campbell, J.M.; Marcinowski, E.C.; Latta, J.; Michel, G.F. Different assessment tasks produce different estimates of handedness stability during the eight to 14 month age period. Infant Behav. Dev. 2015, 39, 67-80. [CrossRef]

138. Ferre, C.L.; Babik, I.; Michel, G.F. A perspective on the development of hemispheric specialization, infant handedness, and cerebral palsy. Cortex 2020, 127, 208-220. [CrossRef]

139. Schaafsma, S.M.; Riedstra, B.J.; Pfannkuche, K.A.; Bouma, A.; Groothuis, T.G.G. Epigenesis of be-havioural lateralization in humans and other animals. Philos. Trans. R. Soc. B 2009, 364, 915-927. [CrossRef]

140. Ramsay, D.S. Onset of unimanual handedness in infants. Infant Behav. Dev. 1980, 3, 377-385. [CrossRef]

141. Michel, G.F.; Tyler, A.N.; Ferre, C.; Sheu, C.-F. The manifestation of infant hand-use preferences when reaching for objects during the seven- to thirteen-month age period. Dev. Psychobiol. 2006, 48, 436-443. [CrossRef] [PubMed]

142. Ferre, C.L.; Babik, I.; Michel, G.F. Development of infant prehension handedness: A longitudinal analysis during the 6- to 14-month age period. Infant Behav. Dev. 2010, 33, 492-502. [CrossRef] [PubMed]

143. Marcinowski, E.C.; Campbell, J.M.; Faldowski, R.A.; Michel, G.F. Do hand preferences predict stacking skill during infancy? Dev. Psychobiol. 2016, 58, 958-967. [CrossRef]

144. Flindall, J.W.; Gonzalez, C.L.R. Wait wait, don't tell me: Handedness questionnaires do not predict hand preference for grasping. Laterality Asymmetries Body Brain Cogn. 2018, 24, 176-196. [CrossRef]

145. Tran, U.S.; Voracek, M. Don't expect the unexpectable: Commentary to Flindall and Gonzalez 2018. Laterality Asymmetries Body Brain Cogn. 2018, 24, 197-200. [CrossRef]

146. Dragovic, M. Towards an improved measure of the Edinburgh handedness inventory: A one-factor con-generic measurement model using confirmatory factor analysis. Laterality 2004, 9, 411-419. [CrossRef] [PubMed]

147. Edlin, J.M.; Leppanen, M.; Fain, R.J.; Hackländer, R.P.; Hanaver-Torrez, S.D.; Lyle, K.B. On the use (and misuse?) of the Edinburgh Handedness Inventory. Brain Cogn. 2015, 94, 44-51. [CrossRef]

148. Prichard, E.; Propper, R.E.; Christman, S.D. Degree of Handedness, but not Direction, is a Systematic Predictor of Cognitive Performance. Front. Psychol. 2013, 4, 9. [CrossRef]

149. Esseily, R.; Jacquet, A.Y.; Fagard, J. Handedness for grasping objects and pointing and the develop-ment of language in 14-monthold infants. Laterality Asymmetries Body Brain Cogn. 2011, 16, 565-585. [CrossRef]

150. Jacquet, A.Y.; Esseily, R.; Rider, D.; Fagard, J. Handedness for grasping objects and declarative point-ing: A longitudinal study. Dev. Psychobiol. 2012, 54, 36-46. [CrossRef]

151. Michel, G.F.; Babik, I.; Sheu, C.-F.; Campbell, J.M. Latent classes in the developmental trajectories of infant handedness. Dev. Psychol. 2014, 50, 349-359. [CrossRef]

152. Bishop, D.V.M. Handedness and Developmental Disorder. Am. J. Psychol. 1993, 106, 294. [CrossRef]

153. Hausmann, M.; Kirk, I.J.; Corballis, M.C. Influence of task complexity on manual asymmetries. Cortex 2004, 40, 103-110. [CrossRef]

154. Bryden, M.P.; Singh, M.; Steenhuis, R.; Clarkson, K.L. A behavioural measure of hand preference as opposed to hand skill. Neuropsychologia 1994, 32, 991-999. [CrossRef]

155. Wolff, P.H.; Michel, G.F.; Ovrut, M.R. Rate and timing precision of motor coordination in Develop-mental Dyslexia. Dev. Psychol. 1990, 26, 82-89. [CrossRef]

156. Gonzalez, S.L.; Nelson, E.L. Addressing the gap: A blueprint for studying bimanual hand preference in infants. Front. Psychol. 2015, 6, 560. [CrossRef] [PubMed]

157. Kuo, Y.-L.; Fisher, B.E. Relationship between interhemispheric inhibition and bimanual coordination: Absence of instrument specificity on motor performance in professional musicians. Exp. Brain Res. 2020, 238, 2921-2930. [CrossRef] [PubMed]

158. Papadatou-Pastou, M.; Ntolka, E.; Schmitz, J.; Martin, M.; Munafò, M.R.; Ocklenburg, S.; Paracchini, S. Human handedness: A meta-analysis. Psychol. Bull. 2020, 146, 481-524. [CrossRef]

159. Hickok, G. The cortical organization of speech processing: Feedback control and predictive coding the context of a dual-stream model. J. Commun. Disord. 2012, 45, 393-402. [CrossRef] [PubMed]

160. Hickok, G.; Poeppel, D. The cortical organization of speech processing. Nat. Rev. Neurosci. 2007, 8, 393-402. [CrossRef] 
161. Pulvermüller, F.; Fadiga, L. Active perception: Sensorimotor circuits as a cortical basis for language. Nat. Rev. Neurosci. 2010, 11, 351-360. [CrossRef]

162. Freund, H.-J.; Jeannerod, M.; Hallett, M.; Leiguarda, R. Higher-Order Motor Disorders: From Neuroanatomy and Neurobiology to Clinical Neurology; Oxford University Press: Oxford, UK, 2005.

163. Tremblay, P.; Deschamps, I.; Gracco, V. Neurobiology of speech production: A motor control perspective. In Neurobiology of Language; Hickok, G., Small, S., Eds.; Elsevier: London, UK, 2016; pp. 741-750.

164. Binkofski, F.; Buccino, G. Motor functions of the Broca's region. Brain Lang. 2004, 89, 362-369. [CrossRef]

165. Higuchi, S.; Chaminade, T.; Imamizu, H.; Kawato, M. Shared neural correlates for language and tool use in Broca's area. NeuroReport 2009, 20, 1376-1381. [CrossRef] [PubMed]

166. Tremblay, P.; Gracco, V.L. Contribution of the pre-SMA to the production of words and non-speech oral motor gestures, as revealed by repetitive transcranial magnetic stimulation (rTMS). Brain Res. 2009, 1268, 112-124. [CrossRef] [PubMed]

167. Gentilucci, M. Grasp observation influences speech production. Eur. J. Neurosci. 2003, 17, 179-184. [CrossRef]

168. Zwicker, J.G.; Missiuna, C.; Harris, S.R.; Boyd, L.A. Brain activation associated with motor skill practice in children with developmental coordination disorder: An fMRI study. Int. J. Dev. Neurosci. 2010, 29, 145-152. [CrossRef] [PubMed]

169. Bizzi, E.; Ajemian, R.J. From motor planning to execution: A sensorimotor loop perspective. J. Neurophysiol. 2020, 124, 1815-1823. [CrossRef]

170. Gentner, R.; Gorges, S.; Weise, D.; Kampe, K.; Buttmann, M.; Classen, J. Encoding of motor skill in the cor-ticomuscular system of musicians. Curr. Biol. 2010, 20, 1869-1874. [CrossRef] [PubMed]

171. Yang, Q.; Logan, D.; Giszter, S.F. Motor primitives are determined in early development and are then robustly conserved into adulthood. Proc. Natl. Acad. Sci. USA 2019, 116, 12025-12034. [CrossRef]

172. Brumley, M.R.; Kauer, S.D.; Swann, H.E. Developmental plasticity of coordinated action patterns in the perinatal rat. Dev. Psychobiol. 2015, 57, 409-420. [CrossRef]

173. Brumley, M.R.; Robinson, S.R. Sensory feedback alters spontaneous limb movements in newborn rats: Effects of unilateral forelimb weighting. Dev. Psychobiol. 2013, 55, 323-333. [CrossRef] [PubMed]

174. Brumley, M.R.; Strain, M.M.; Devine, N.; Bozeman, A.L. The Spinal Cord, Not to Be Forgotten: The Final Common Path for Development, Training and Recovery of Motor Function. Perspect. Behav. Sci. 2018, 41, 369-393. [CrossRef]

175. Robinson, S.R. Conjugate limb coordination after experience with an interlimb yoke: Evidence for motor learning in the rat fetus. Dev. Psychobiol. 2005, 47, 328-344. [CrossRef]

176. Robinson, S.R. Spinal mediation of motor learning and memory in the rat fetus. Dev. Psychobiol. 2015, 57, 421-434. [CrossRef]

177. Robinson, S.R. Yoke Motor Learning in the Fetal Rat: A Model System for Prenatal Behavioral Development. Fetal Dev. 2016, 10, 43-66.

178. Robinson, S.R.; Kleven, G.A.; Brumley, M. Prenatal Development of Interlimb Motor Learning in the Rat Fetus. Infancy 2008, 13, 204-228. [CrossRef] [PubMed]

179. Sauerbrei, B.; Guo, J.-Z.; Cohen, J.D.; Mischiati, M.; Guo, W.; Kabra, M.; Verma, N.; Mensh, B.; Branson, K.; Hantman, A.W. Cortical pattern generation during dexterous movement is input-driven. Nat. Cell Biol. 2020, 577, 386-391. [CrossRef] [PubMed]

180. Amaya, K.A.; Smith, K.S. Neurobiology of habit formation. Curr. Opin. Behav. Sci. 2018, 20, 145-152. [CrossRef]

181. Ohbayashi, M.; Picard, N.; Strick, P.L. Inactivation of the dorsal premotor area disrupts internally gener-ated, but not visually guided, sequential movements. J. Neurosci. 2016, 36, 1971-1976. [CrossRef] [PubMed]

182. Rathelot, J.A.; Strick, P.L. Muscle representation in the macaque motor cortex: An anatomical perspec-tive. Proc. Natl. Acad. Sci. USA 2006, 103, 8257-8262. [CrossRef]

183. Rathelot, J.-A.; Strick, P.L. Subdivisions of primary motor cortex based on cortico-motoneuronal cells. Proc. Natl. Acad. Sci. USA 2009, 106, 918-923. [CrossRef] [PubMed]

184. Muir, R.; Lemon, R. Corticospinal neurons with a special role in precision grip. Brain Res. 1983, 261, 312-316. [CrossRef]

185. Keane, A. A common neural mechanism for speech perception and movement initiation specialized for place of articulation. Cogent Psychol. 2016, 3, 1233649. [CrossRef]

186. Pulvermuller, F.; Huss, M.; Kherif, F.; Martin, F.M.D.P.; Hauk, O.; Shtyrov, Y. Motor cortex maps articulatory features of speech sounds. Proc. Natl. Acad. Sci. USA 2006, 103, 7865-7870. [CrossRef]

187. Michel, G.F. Self-generated experience and the development lateralized neurobehavioral organization in infants. In Advances in the Study of Behavior; Rosenblatt, J.S., Beer, C.G., Busnel, M.C., Slater, P.J.B., Eds.; Academic Press: New York, NY, USA, 1987; Volume 17, pp. 61-83.

188. Villar-Rodríguez, E.; Palomar-García, M.; Hernández, M.; Adrián-Ventura, J.; Olcina-Sempere, G.; Parcet, M.; Ávila, C. Lefthanded musicians show a higher probability of atypical cerebral dominance for language. Hum. Brain Mapp. 2020, 41, $2048-2058$. [CrossRef] [PubMed]

189. Schmahmann, J.; MacMore, J.; Vangel, M. Cerebellar stroke without motor deficit: Clinical evidence for motor and non-motor domains within the human cerebellum. Neuroscience 2009, 162, 852-861. [CrossRef] [PubMed]

190. Kavaklioglu, T.; Guadalupe, T.; Zwiers, M.; Marquand, A.; Onnink, M.; Shumskaya, E.; Brunner, H.; Fernandez, G.; Fisher, S.E.; Francks, C. Structural asymmetries of the human cerebellum in relation to cerebral cortical asymmetries and handedness. Brain Struct. Funct. 2017, 222, 1611-1623. [CrossRef] 
191. Polat, G. Evaluation of relationship between middle cerebellar peduncle asymmetry and dominant hand by diffusion tensor imaging. Folia Morphol. 2019, 78, 481-486. [CrossRef]

192. Flowers, K.A.; Hudson, J.M. Motor laterality as an indicator of speech laterality. Neuropsychology 2013, 27, 256-265. [CrossRef]

193. Hodgson, J.C.; Hirst, R.J.; Hudson, J.M. Hemispheric speech lateralisation in the developing brain is related to motor praxis ability. Dev. Cogn. Neurosci. 2016, 22, 9-17. [CrossRef]

194. Hodgson, J.C.; Hudson, J.M. Atypical speech lateralization in adults with developmental coordination disorder demonstrated using functional transcranial Doppler ultrasound. J. Neuropsychol. 2016, 11, 1-13. [CrossRef] [PubMed]

195. Hodgson, J.C.; Hudson, J.M. Speech lateralization and motor control. In Cerebral Lateralization and Cognition: Evolutionary and Developmental Investigations of Motor Biases; Forrester, G., Hudry, K., Lindell, A., Hopkins, W.D., Eds.; Elsevier: Amsterdam, The Netherlands, 2018; pp. 147-178. [CrossRef]

196. Cowell, P.; Gurd, J. Handedness and the Corpus Callosum: A Review and Further Analyses of Discordant Twins. Neuroscience 2018, 388, 57-68. [CrossRef]

197. Gazzaniga, M.S. Review of the split brain. J. Neurol. 1975, 209, 75-79. [CrossRef]

198. Denenberg, V.H.; Kertesz, A.; Cowell, P.E. A factor analysis of the human's corpus callosum. Brain Res. 1991, 548, 126-132. [CrossRef]

199. Kuypers, H.G.J.M. A new look at the organization of the motor system. In Progress in Brain Research: Vol. 57. Anatomy of Descending Pathways to the Spinal Cord; Kuypers, H.G.J.M., Martin, G.F., Eds.; Elsevier: New York, NY, USA, 1982; pp. 381-404.

200. Preilowski, B.F. Possible contribution of the anterior forebrain commissures to bilateral motor coordination. Neuropsychologia 1972, 10, 267-277. [CrossRef]

201. Preilowski, B. Bilateral Motor Interaction: Perceptual-Motor Performance of Partial and Complete "Split-Brain" Patients. In Cerebral Localization; Springer: Berlin/Heidelberg, Germany, 1975; pp. 115-132.

202. Selnes, O.A. The corpus callosum: Some anatomical and functional considerations with special refer-ence to language. Brain Lang. 1974, 1, 111-139. [CrossRef]

203. Sperry, R.W.; Gazzaniga, M.S.; Bogen, J.E. Interhemispheric relationships: The neocortical commissures; syndromes of hemispheric disconnection. In Handbook of Clinical Neurology; Vinken, P.J., Bruyn, G.W., Eds.; North Holland: Amsterdam, The Netherlands, 1969; Volume 4, pp. 273-290.

204. Zaidel, D.; Sperry, R.W. Long-term motor coordination problems following cerebral commissurotomy in man. Neuropsychologia 1977, 15, 193-204. [CrossRef]

205. Lassonde, M.; Sauerwein, H.; Geoffroy, G.; Decarie, M. Effects of early and late transection of the corpus callosum in children. A study of tactile and tactuomotor transfer and integration. Brain 1986, 109, 953-967. [CrossRef] [PubMed]

206. Lassonde, M.; Sauerwein, H.; Chicoine, A.J.; Geoffroy, G. Absence of disconnexion syndrome in callo-sal agenesis and early callosotomy: Brain reorganization or lack of structural specificity during ontogeny? Neuropsychologia 1991, 29, 481-495. [CrossRef]

207. Innocenti, G.M.; Price, D.J. Exuberance in the development of cortical networks. Nat. Rev. Neurosci. 2005, 6, 955-965. [CrossRef]

208. Blumenfeld-Katzir, T.; Pasternak, O.; Dagan, M.; Assaf, Y. Diffusion MRI of Structural Brain Plasticity Induced by a Learning and Memory Task. PLoS ONE 2011, 6, e20678. [CrossRef]

209. Markham, J.A.; Herting, M.M.; Luszpak, A.E.; Juraska, J.M.; Greenough, W.T. Myelination of the cor-pus callosum in male and female rats following complex environment housing during adulthood. Brain Res. 2009, 1288, 9-17. [CrossRef]

210. Salamy, A. Commissural transmission: Maturational changes in humans. Science 1978, 200, 1409-1411. [CrossRef] [PubMed]

211. Yakovlev, P.J.; Lecours, A.R. The myelinogenetic cycles or regional maturation of the brain. In Regional Development of the Brain; Minkowski, A., Ed.; Blackwell: Oxford, UK, 1967; pp. 3-70.

212. Knyazeva, M.G. Splenium of Corpus Callosum: Patterns of Interhemispheric Interaction in Children and Adults. Neural Plast. 2013, 2013, 1-12. [CrossRef]

213. Stroganova, T.A.; Orekhova, E.V.; Posikera, I.N. EEG alpha rhythm in infants. Clin. Neurophysiol. 1999, 110, 997-1012. [CrossRef]

214. Farber, D.A.; Knyazeva, M.G. Electrophysiological correlates of interhemispheric interaction in on-togenesis. In Pediatric Behavioural Neurology; Ramaekers, G., Njiokiktjien, C., Eds.; Suyi Publications: Amsterdam, The Netherlands, 1991; Volume 3, pp. 86-99.

215. Jones, E.G. Development of connectivity in the cerebral cortex. In Studies in Develozpmental Neurobiology; Cowan, W.M., Ed.; Oxford University Press: New York, NY, USA, 1981; pp. 354-394.

216. Kaas, J.H. The functional organization of somatosensory cortex in primates. Ann. Anat. Anat. Anz. 1993, 175, 509-518. [CrossRef]

217. Georgopoulos, A.P.; Kalaska, J.F.; Caminiti, R. Relations Between Two-Dimensional Arm Movements and Single-Cell Discharge in Motor Cortex and Area 5: Movement Direction Versus Movement End Point. In Hand Function and the Neocortex; Springer: Berlin/Heidelberg, Germany, 1985; pp. 175-183.

218. Streri, A.; Gentaz, E. Intermanual and Intermodal Transfer in Human Newborns: Neonatal Behavioral Evidence and Neurocognitive Approach. 2012. Available online: http://www.intechopen.com/books/neuroimaging-cognitive-and-clinical-neuroscience/ intermanual-and-intermodal-transfer-in-human-newborns-neonatal-behavioral-evidence-and-neurocognitiv (accessed on 29 May 2021).

219. Lejeune, F.; Audeoud, F.; Marcus, L.; Streri, A.; Debillon, T.; Gentaz, E. The Manual Habituation and Discrimination of Shapes in Preterm Human Infants from 33 to 34+6 Post-Conceptional Age. PLoS ONE 2010, 5, e9108. [CrossRef] [PubMed] 
220. Michel, G.F.; Ovrut, M.R.; Harkins, D.A. Intermanual transfer of tactile discrimination learning during infancy. In Proceedings of the International Conference on Infant Studies, New York, NY, USA, 21 April 1984.

221. Michel, G.F. Development of infant manual skills: Motor programs, schemata, or dynamic systems. In The Development of Timing Control and Temporal Organization in Coordinated Action; Fagard, J., Wolff, P.H., Eds.; Elsevier: Amsterdam, The Netherlands, 1991; pp. 175-199.

222. Trevarthen, C. Functional relations of disconnected hemispheres with the brain stem and with each other: Monkey and man. In Hemispheric Disconnection and Cerebral Function; Kinsbourne, M., Smith, W.L., Eds.; C.C. Thomas: Springfield, IL, USA, 1974; pp. 187-207.

223. Trevarthen, C. Manipulative strategies of baboons and origins of cerebral asymmetry. In Asymmetrical Functions of the Brain; Kinsbourne, M., Ed.; Cambridge University Press: New York, NY, USA, 1978; pp. 36-89.

224. Černáček, J.; Podivinský, F. Ontogenesis of handedness and somatosensory cortical response. Neuropsychologia 1971, 9, $219-232$. [CrossRef]

225. Volz, L.J.; Hillyard, S.A.; Miller, M.B.; Gazzaniga, M.S. Unifying control over the body: Consciousness and cross-cueing in split-brain patients. Brain 2018, 141, e15. [CrossRef] [PubMed]

226. Connolly, K.; Stratton, P. Developmental changes ln associated movements. Dev. Med. Child. Neurol. 1968, 10, 49-56. [CrossRef]

227. Wolff, P.H.; Gunnoe, C.E.; Cohen, C. Associated movements as a measure of developmental age. Dev. Med. Child. Neurol. 1983, 25, 417-429. [CrossRef] [PubMed]

228. Dennis, M. Impaired sensory and motor differentiation with corpus callosum agenesis: A lack of callosal inhibition during ontogeny? Neuropsychologia 1976, 14, 455-469. [CrossRef]

229. Milner, A.O.; Jeeves, M.A. A review of behavioral studies of agenesis of the corpus callosum. In Structure and Function of the Cerebral Commissures; IRussell, S., van Hof, M.W., Rerlucchi, G., Eds.; University Park Press: Baltimore, MD, USA, 1979.

230. Kimmerle, M.; Mick, L.A.; Michel, G.F. Bimanual role-differentiated toy play during infancy. Infant Behav. Dev. 1995, 18, $299-307$. [CrossRef]

231. Liuzzi, G.; Hoerniß, V.; Zimerman, M.; Gerloff, C.; Hummel, F.C. Coordination of uncoupled bi-manual movements by strictly timed interhemispheric connectivity. J. Neurosci. 2011, 31, 9111-9117. [CrossRef] [PubMed]

232. Goldfield, E.C.; Michel, G.F. The ontogeny of infant bimanual reaching during the first year. Infant Behav. Dev. 1986, 9, 81-89. [CrossRef]

233. Goldfield, E.C.; Michel, G.F. Spatio-temporal linkage in infant interlimb coordination. Dev. Psychobiol. 1986, 19, 259-264. [CrossRef] [PubMed]

234. Yokoi, A.; Bai, W.; Diedrichsen, J. Restricted transfer of learning between unimanual and bimanual finger sequences. J. Neurophysiol. 2017, 117, 1043-1051. [CrossRef]

235. Scharoun, S.M.; Bryden, P.J. Hand preference, performance abilities, and hand selection in children. Front. Psychol. $2014,5,82$. [CrossRef]

236. Kalisch, T.; Wilimzig, C.; Kleibel, N.; Tegenthoff, M.; Dinse, H.R. Age-Related Attenuation of Dominant Hand Superiority. PLoS ONE 2006, 1, e90. [CrossRef] [PubMed]

237. Dehaene-Lambertz, G.; Dehaene, S.; Hertz-Pannier, L. Functional Neuroimaging of Speech Perception in Infants. Science 2002, 298, 2013-2015. [CrossRef]

238. Dehaene-Lambertz, G.; Pena, M.; Christophe, A.; Landrieu, P. Phoneme perception in a neonate with a left sylvian infarct. Brain Lang. 2004, 88, 26-38. [CrossRef]

239. Dehaene-Lambertz, G.; Montavont, A.; Jobert, A.; Allirol, L.; Dubois, J.; Hertz-Pannier, L.; Dehaene, S. Language or music, mother or Mozart? Structural and environmental influences on infants' language networks. Brain Lang. 2010, 114, 53-65. [CrossRef]

240. Kuhl, P.K. Discrimination of speech by nonhuman animals: Basic auditory sensitivities conducive to the perception of speechsound categories. J. Acoust. Soc. Am. 1981, 70, 340-349. [CrossRef]

241. Chen, X.; Lu, B.; Yan, C.-G. Reproducibility of R-fMRI metrics on the impact of different strategies for mul-tiple comparison correction and sample sizes. Hum. Brain Mapp. 2018, 39, 300-318. [CrossRef]

242. Cremers, H.R.; Wager, T.D.; Yarkoni, T. The relation between statistical power and inference in fMRI. PLoS ONE 2017, 12, e0184923. [CrossRef] [PubMed]

243. Poldrack, R.A.; Baker, C.I.; Durnez, J.; Gorgolewski, K.J.; Matthews, P.M.; Munafò, M.; Nichols, T.E.; Poline, J.B.; Vul, E.; Yarkoni, T.; et al. Scanning the horizon: Future challenges for neuroimaging research. Nat. Rev. Neurosci. 2017, 18, 115-126. [CrossRef] [PubMed]

244. Schwartz, C.; Michel, G.F. Postural and positional effects on manual coordination of 10-32 hour old neonates. In Proceedings of the 24th Annual meeting of the International Society for Developmental Psychobiology, New Orleans, LA, USA, 8 November 1991.

245. Schwartz, C.B.; Michel, G.F. Posture and head orientation direction affects patterns of manual coordi-nation in 11-25 hour old human neonates. In Proceedings of the Eighth International Conference on Infant Studies, Miami, FL, USA, 15 May 1992.

246. Leong, A.T.L.; Gu, Y.; Chan, Y.-S.; Zheng, H.; Dong, C.M.; Chan, R.W.; Wang, X.; Liu, Y.; Tan, L.H.; Wu, E.X. Optogenetic fMRI interrogation of brain-wide central vestibular pathways. Proc. Natl. Acad. Sci. USA 2019, 116, 10122-10129. [CrossRef] [PubMed]

247. Ferrè, E.R.; Haggard, P. Vestibular cognition: State-of-the-art and future directions. Cogn. Neuropsychol. 2020, 37, 413-420. [CrossRef] [PubMed] 
248. Smyser, C.D.; Snyder, A.Z.; Neil, J.J. Functional connectivity MRI in infants: Exploration of the func-tional organization of the developing brain. Neuroimage 2011, 56, 1437-1452. [CrossRef]

249. Zhang, D.; Raichle, M.E. Disease and the brain's dark energy. Nat. Rev. Neurol. 2010, 6, 15-28. [CrossRef] [PubMed]

250. Heuvel, M.I.V.D.; Thomason, M.E. Functional Connectivity of the Human Brain in Utero. Trends Cogn. Sci. 2016, 20, 931-939. [CrossRef]

251. Elliott, M.L.; Knodt, A.R.; Ireland, D.; Morris, M.L.; Poulton, R.; Ramrakha, S.; Sison, M.L.; Moffitt, T.E.; Caspi, A.; Hariri, A.R. What Is the Test-Retest Reliability of Common Task-Functional MRI Measures? New Empirical Evidence and a Meta-Analysis. Psychol. Sci. 2020, 31, 792-806. [CrossRef]

252. Hepper, P.G.; McCartney, G.R.; Shannon, E.A. Lateralised behavior in first trimester human fetuses. Neuropsychologia 1998, 36, 531-534. [CrossRef]

253. Hepper, P.G.; Shahidullah, S.; White, R. Handedness in the human fetus. Neuropsychologia 1991, 29, 1107-1111. [CrossRef]

254. Hepper, P.G.; Wells, D.L.; Lynch, C. Prenatal thumb sucking is related to postnatal handedness. Neuropsychologia 2005, 43, 313-315. [CrossRef]

255. de Vries JI, P.; Wimmers, R.H.; Ververs IA, P.; Hopkins, B.; Savelsbergh GJ, P.; Van Geijn, H.P. Fe-tal handedness and head position preference: A developmental study. Dev. Psychobiol. 2001, 39, 171-178. [CrossRef]

256. Ocklenburg, S.; Schmitz, J.; Moinfar, Z.; Güntürkün, O. Epigenetic regulation of lateralized fetal spinal gene expression underlies hemispheric asymmetries. eLife 2017, 6, e22784. [CrossRef]

257. Dunn, P.M. Congenital postural deformities. Br. Med. Bull. 1976, 32, 71-76. [CrossRef] [PubMed]

258. Caesar, P. Postural Behavior in Newborn Infants; J. B. Lippincott: Philadelphia, PA, USA, 1979.

259. Schulte, F.J. The neurological development of the neonate. In Scientific Foundations of Pediatrics; Davis, J.A., Debbing, J., Eds.; Saunders: Philadelphia, PA, USA, 1974; pp. 587-615.

260. Donkelaar, H.J.T.; Lammens, M.; Wesseling, P.; Hori, A.; Keyser, A.; Rotteveel, J. Development and malformations of the human pyramidal tract. J. Neurol. 2004, 251, 1429-1442. [CrossRef] [PubMed]

261. Turkewitz, G. The development of lateral differences in the human infant. In Lateralization in the Nervous System; Harnad, S., Doty, R.W., Goldstein, I., Jaynes, J., Krauthammer, G., Eds.; Academic Press: New York, NY, USA, 1977; pp. 251-260.

262. Rönnqvist, L.; Hopkins, B.; van Emmerik, R.; de Groot, L. Lateral biases in head turning and the Moro response in the human newborn: Are they both vestibular in origin? Dev. Psychobiol. 1998, 33, 339-349. [CrossRef]

263. Michel, G.F.; Goodwin, R. Intrauterine birth position predicts newborn supine head position preferences. Infant Behav. Dev. 1979, 2, 29-38. [CrossRef]

264. Rönnqvist, L.; Hopkins, B. Head position preference in the human newborn: A new look. Child. Dev. 1998, 69, 13-23. [CrossRef]

265. Annett, M. The distribution of manual asymmetry. Br. J. Psychol. 1972, 63, 343-358. [CrossRef] [PubMed]

266. McFarland, K. Motor control: Pyramidal, extrapyramidal, and limbic motor control. In Handbook of Neuroscience for the Behavioral Sciences; Berntson, G.G., Cacioppo, J.T., Eds.; Wiley: Hoboken, NJ, USA, 2009; Volume 1, pp. 431-453.

267. Spinelli, D.N.; Jensen, F.E. Plasticity, experience and resource allocation in motor cortex and hypothalamus. In Conditioning. Advances in Behavioral Biology; Woody, C.D., Ed.; Springer: Boston, MA, USA, 1982; Volume 26, pp. 651-661. [CrossRef]

268. Tan, U.; Ors, R.; Kürkçüogu, M.; Kutlu, N. The Lateralization of the Grasp Reflex in Human Newborns. Int. J. Neurosci. 1991, 62, 1-8. [CrossRef]

269. Caplan, P.J.; Kinsbourne, M. Baby Drops the Rattle: Asymmetry of Duration of Grasp by Infants. Child. Dev. 1976, $47,532$. [CrossRef]

270. Campbell, J.M.; Marcinowski, E.C.; Michel, G.F. The development of neuromotor skills and hand preference during infancy. Dev. Psychobiol. 2017, 60, 165-175. [CrossRef]

271. Campbell, J.M.; Marcinowski, E.C.; Babik, I.; Michel, G.F. The Influence of a Hand-use Preference for Acquiring Objects on the Development of a Hand-use Preference for Unimanual Manipulation from 6 to 14 Months. Infant Behav. Dev. 2015, 39, 107-117. [CrossRef]

272. Hinojosa, T.; Sheu, C.-F.; Michel, G.F. Infant hand-use preferences for grasping objects contributes to the development of a hand-use preference for manipulating objects. Dev. Psychobiol. 2003, 43, 328-334. [CrossRef]

273. Babik, I.; Michel, G.F. Development of role-differentiated bimanual manipulation in infancy: Part 1 . The emergence of the skill. Dev. Psychobiol. 2015, 58, 243-256. [CrossRef]

274. Nelson, E.L.; Campbell, J.M.; Michel, G.F. Early handedness in infancy predicts language ability in toddlers. Dev. Psychol. 2014, 50, 809-814. [CrossRef]

275. Bryden, M.; Steenhuis, R.E. Issues in the assessment of handedness. In Cerebral Laterality: Theory and Research; Kitterle, F.L., Ed.; Erlbaum Associates, Inc.: Hillsdale, NJ, USA, 1991; pp. 35-51.

276. Latta, J.A. Predicting Child Handedness from Measures of Infant and Toddler Handedness. Master's Thesis, University of North Carolina, Greensboro, NC, USA, 2020.

277. Casasanto, D. Embodiment of abstract concepts: Good and bad in right- and left-handers. J. Exp. Psychol. Gen. 2009, 138, 351-367. [CrossRef]

278. Casasanto, D.; Henetz, T. Handedness Shapes Children's Abstract Concepts. Cogn. Sci. 2011, 36, 359-372. [CrossRef] [PubMed]

279. Jones, G.V.; Martin, M. Language dominance, handedness and sex: Recessive X-linkage theory and test. Cortex 2010, 46, 781-786. [CrossRef] 
280. Knecht, S.; Dräger, B.; Deppe, M.; Bobe, L.; Lohmann, H.; Flöel, A.; Ringelstein, E.-B.; Henningsen, H. Handedness and hemispheric language dominance in healthy humans. Brain 2000, 123, 2512-2518. [CrossRef] [PubMed]

281. Kotwica, K.A.; Ferre, C.L.; Michel, G.F. Relation of stable hand-use preferences to the development of skill for managing multiple objects from 7 to 13 months of age. Dev. Psychobiol. 2008, 50, 519-529. [CrossRef]

282. Bruner, J.S. Beyond the Information Given; W. W. Norton and Co.: New York, NY, USA, 1973.

283. Marcinowski, E.C.; Campbell, J.M. Building on what you have learned. Int. J. Behav. Dev. 2017, 41, 341-349. [CrossRef]

284. Nelson, E.L.; Gonzalez, S.L.; Coxe, S.; Campbell, J.M.; Marcinowski, E.C.; Michel, G.F. Toddler hand preference trajectories predict 3-year language outcome. Dev. Psychobiol. 2017, 59, 876-887. [CrossRef]

285. Gonzalez, S.L.; Campbell, J.M.; Marcinowski, E.C.; Michel, G.F.; Coxe, S.; Nelson, E.L. Preschool language ability is predicted by toddler hand preference trajectories. Dev. Psychol. 2020, 56, 699-709. [CrossRef]

286. Babik, I.; Cruz-Boyer, Q.; Belarski, A.C.; Gardner, E.S.; Michel, G.F. The Relation of Unimanual and Bimanual Manipulation to the Tool-Use Development during Infancy. Available online: https:/ /www.preprints.org/manuscript/202105.0126/v1 (accessed on 23 April 2021).

287. D'Souza, D.; Karmiloff-Smith, A. When modularization fails to occur: A developmental perspective. Cogn. Neuropsychol. 2011, 28, 276-287. [CrossRef]

288. Martzog, P.; Stoeger, H.; Suggate, S. Relations between Preschool Children's Fine Motor Skills and General Cognitive Abilities. J. Cogn. Dev. 2019, 20, 443-465. [CrossRef]

289. Pezzulo, G. Grounding Procedural and Declarative Knowledge in Sensorimotor Anticipation. Mind Lang. 2011, 26, 78-114. [CrossRef]

290. Cameron, C.E.; Brock, L.L.; Murrah, W.M.; Bell, L.H.; Worzalla, S.L.; Grissmer, D.; Morrison, F.J. Fine Motor Skills and Executive Function Both Contribute to Kindergarten Achievement. Child. Dev. 2012, 83, 1229-1244. [CrossRef] [PubMed]

291. Grissmer, D.; Grimm, K.J.; Aiyer, S.M.; Murrah, W.M.; Steele, J.S. Fine motor skills and early compre-hension of the world: Two school readiness indicators. Dev. Psychol. 2010, 46, 1008-1017. [CrossRef] [PubMed]

292. Suggate, S.; Pufke, E.; Stoeger, H. Children's fine motor skills in kindergarten predict reading in grade 1. Early Child. Res. Q. 2019, 47, 248-258. [CrossRef]

293. Suggate, S.; Stoeger, H. Fine Motor Skills Enhance Lexical Processing of Embodied Vocabulary: A Test of the Nimble-Hands, Nimble-Minds Hypothesis. Q. J. Exp. Psychol. 2017, 70, 2169-2187. [CrossRef]

294. Finlay, B.L. Endless minds most beautiful. Dev. Sci. 2007, 10, 30-34. [CrossRef]

295. Ballantyne, A.O.; Spilkin, A.M.; Hesselink, J.; Trauner, D.A. Plasticity in the developing brain: Intellectual, language and academic functions in children with ischaemic perinatal stroke. Brain 2008, 131, 2975-2985. [CrossRef] 